\title{
Spatio-temporal vegetation dynamics and relationship with climate over East Africa
}

\author{
John Musau ${ }^{1,2}$, Sopan Patil ${ }^{1}$, Justin Sheffield ${ }^{3}$, Michael Marshall ${ }^{2}$ \\ ${ }^{1}$ School of Environment, Natural Resources and Geography; Bangor University, UK \\ $5{ }^{2}$ Climate Change Research Unit SD6, World Agroforestry Centre (ICRAF), Nairobi, Kenya \\ ${ }^{3}$ Department of Civil and Environmental Engineering, Princeton University, Princeton, New Jersey \\ Corresponding Author: John Musau (johnkuyega@gmail.com)
}

\begin{abstract}
Vegetation plays a key role in the global climate system via modification of the water and energy balance. Its
10 coupling to climate is therefore important particularly in the tropics, where severe climate change impacts are expected. Vegetation growth is mutually controlled by temperature and water availability while it modifies regional climate through latent heat flux and changes in albedo. Consequently, understanding how projected climate change will impact vegetation and the forcing of vegetation on climate for various land cover types in East Africa is vital. This study provides an assessment of the vegetation trends in East Africa using Leaf Area Index (LAI) time series for the period 1982 to 2011 ,

15 lead/lag correlation analysis between LAI and climate, a statistical estimation of vegetation feedback on climate using lagged covariance ratios as well as spatial regression analysis. Our results show few significant changes in current LAI trends though persistent declining vegetation trends are shown from Southern Ethiopia extending through Central Kenya into Central Tanzania. Precipitation (temperature) exerts widespread positive (negative) forcing on lagging vegetation except in forests. Positive correlations between the lagging Antecedent Precipitation Index (API) and LAI were dominant compared to

20 temperature. Positive vegetation feedback on precipitation dominates across the region while a stronger negative forcing is exerted on Tmin compared to Tmax. Spatial dependence was also shown as a key component in the vegetation-climate interactions in the region. Given the vital role of land surface dynamics on local and regional climate, these results provide a valuable point of reference for evaluating the land-atmosphere coupling in the region.
\end{abstract}

\section{Introduction}

25 Terrestrial vegetation depend on and affect land surface-atmosphere interactions as the primary link for moisture (evapotranspiration) and energy (latent) exchange through its physiological properties (Leaf Area Index-LAI, rooting depth and stomatal resistance), and its influence on surface roughness, and albedo (Arora, 2002; Bao et al., 2014; Ning et al., 2015). For instance, recent studies have reported a strong land-atmosphere coupling in West Africa, whereby vegetation dynamics play a significant role in regulating the West Africa monsoon and therefore rainfall distribution (Hales et al., 2006;

30 Xue et al., 2012; Zheng and Eltahir, 1998). In South Africa, Williams and Kniveton (2012) reported increases and decreases 
in annual rainfall, based on idealized scenarios of expanding savanna and desert cover, respectively. Recent studies on the climatic impacts of tropical deforestation have consistently shown increased warming and reduced evapotranspiration and precipitation (Snyder, 2010; Snyder et al., 2004). Any alteration to vegetation cover is thus likely to have a strong effect at local, regional and even global scales. The appreciation of spatial and temporal vegetation patterns is therefore important to

5 not only assess landscape conditions but also to improve land surface model predictions and identify significant regional and global scale climate teleconnections.

The availability of long-term, repetitive satellite-derived datasets has greatly improved the monitoring and characterization of the land surface at varying spatial and temporal scales. Multispectral band combinations of these datasets have aided the retrieval of long time series of land surface variables widely used to examine trends in vegetation dynamics at global,

10 regional and national scales (Bao et al., 2014; Julien and Sobrino, 2009), impacts of vegetation on water and energy flux (Hu et al., 2009) as well as the correlation between vegetation and climate conditions (Bao et al., 2014). Particularly, Leaf Area Index (LAI), which is defined, in broadleaf canopies, as the one-sided green leaf area per unit vegetated ground area, and in coniferous canopies, as one-half the total needle surface area per unit vegetated ground area. It defines the physiologically functioning surface area for energy, mass and momentum exchange between the vegetated land surface and the planetary

15 boundary layer hence widely used by the global change research community to assess and quantify vegetation dynamics and their effects (Bobée et al., 2012; Cook and Pau, 2013; Pfeifer et al., 2014). This dataset is also a pertinent input or state variable in land surface process-based models for simulating land-atmosphere dynamics. For instance, Hu et al. (2009) used satellite-derived LAI data to scale up estimates of evapotranspiration based on an energy balance model while Verhoef et al. (2012) used LAI data to account for the effect of canopy in calculation of surface soil heat flux. In Ford and Quiring (2013),

20 LAI was used to estimate effects of dynamic inter-annual vegetation conditions on soil moisture and they recommended that dynamic, rather than static, LAI parameters should be used to provide better estimates of intensity and duration of drought conditions.

Studies on the causes of variations in vegetation have shown that climatic factors, particularly precipitation and temperature, significantly influence vegetation dynamics (Jiapaer et al., 2015; Liu et al., 2015; Montaldo et al., 2008; Tagesson et al.,

25 2015). For instance, Tagesson et al. (2015) reported a strong link between inter-annual variation in species composition and rainfall distribution in a semiarid savanna grassland study site in West Africa region. On the other hand, vegetation feedback on climate has gained a lot of interest among climate and earth system studies in the recent past (Alessandri and Navarra, 2008; Delire et al., 2011; Ge et al., 2014; Liu et al., 2006; Oguntunde et al., 2014). The key mechanisms reported in the vegetation feedback relate to changes in partitioning of surface net radiation between latent heat and sensible heat (Ge et al.,

30 2014; Wilson et al., 2002), vegetation-induced enhanced variability of the biosphere-atmosphere system at varying temporal scales (Delire et al., 2011) as well as sensitivity of regional climate to land surface heterogeneity associated with vegetation cover (Lu and Shuttleworth, 2002) among other processes. A multiplicity of statistical and physically-based approaches has been used to assess climate forcing on vegetation as well as vegetation feedback on climate. For instance, Navarra and Tribbia (2005) developed the coupled manifold technique later applied by Alessandri and Navarra (2008) to assess the 
reciprocal forcing of seasonal mean vegetation and rainfall anomalies over land, taking into account both local and remote forcing. Zhou et al. (2007) used a land surface model coupled with an atmospheric model to quantify vegetation-soil impacts on the Sahelian Diurnal Temperature Range changes while Notaro et al. (2006) used instantaneous and lead/lag correlations to assess vegetation-climate feedbacks in the United States. Recently, a statistical approach originally applied in assessing

5 ocean-atmosphere interactions (Frankignoul and Hasselmann, 1977) has been widely applied to quantify vegetation feedbacks on the atmosphere based on observed and simulated datasets (Liu et al., 2006; Nataro et al., 2008; Notaro and Liu, 2007).

The East Africa region, covered in this study, exhibits a wide range of climatic and ecological zones leading to diverse land cover types and land cover change dynamics (Brink et al., 2014). Due to the high dependence of livelihoods on rain-fed

10 agriculture, there is high vulnerability to extreme negative effects of climate change in the region (Ayana et al., 2016; Grace et al., 2014; Pricope et al., 2013). Land cover/use change is a major threat to the ecological systems in East Africa (Brink et al., 2014; Jacobson et al., 2015; Maitima et al., 2009; Pricope et al., 2013). As reported by Jacobson et al. (2015), approximately $30 \%$ of the region has been converted to anthropogenic land cover with Burundi and Rwanda showing the highest proportions of anthropogenic land cover at $85.99 \%$ and $82.27 \%$ respectively. Between 1990 and 2010, Brink et al.

15 (2014) found that agricultural area in East Africa (comprising Djibouti, Eritrea, Ethiopia, Kenya, Somalia, Sudan and Uganda) increased by $28 \%$ with an alarming shift in the rate of deforestation from $0.2 \%$ per year in $1990-2000$ period to 0.4\% per year in 2000-2010 period. Pricope et al. (2013) addressed the spatial interaction between climate, vegetation variations and degradation, and population density changes in the East Africa Horn's pastoral and agro-pastoral livelihoods zones. They established a potential long-term degradation of rangelands mainly due to population pressures and land use

20 change. As noted by Ayana et al. (2016), the frequency of drought in the greater horn of Africa has doubled from once every 6 years to once every 3 years partly contributing to increased resource-based conflicts in the region.

The assessment of emerging vulnerable areas in the region is therefore important in the context of vegetation dynamics and the potential implications on land-atmosphere interactions. Despite the undisputable need for analysis of spatial-temporal vegetation dynamics and their relationship with climatic variables (precipitation and temperature), the region has been

25 inadequately studied at the regional scale and over wide time scales. Consequently, through the analyses of 30 years (1982 to 2011) LAI time series data, this study aimed at providing a new and valuable understanding of the spatial temporal variations of vegetation dynamics in East Africa and relationship with temperature and precipitation. The specific objective of the study was two-fold: 1) to assess trends in LAI from 1982-2011 at a monthly time-step at $8 \mathrm{~km}$ spatial resolution and 2) to evaluate vegetation-climate relationship using correlation and regression analysis and a statistical feedback parameter. 
Hydrol. Earth Syst. Sci. Discuss., doi:10.5194/hess-2016-502, 2016

\section{Study area and data handling}

\subsection{Study area}

Our area of study spanned an area of approximately 2,267,136 $\mathrm{km}^{2}$ (bounded by N5.52 and S11.76 latitude, W28.8 and E41.92 longitude) and comprising the countries of Burundi, Kenya, Tanzania, Rwanda and Uganda, and portions of the

5 Congo, Ethiopia, Malawi, Mozambique, Somalia, South Sudan and Zambia (Figure 1). A broad overview of the relation between climate and the key vegetation zones in the region is described in White (1983). The northward migration of the Intertropical Convergence Zone (ITCZ) in the summer months initiates a bimodal precipitation pattern in the majority of the region with a main rain season during March to May and short (monsoonal) rains during October to November (McNally et al., 2016). The Somalia-Masai ecoregion covers most of Kenya between the highlands and coastal belt as well as the dry

10 lowlands of north and central Tanzania. This ecoregion consists mainly of arid and semi-arid climate with a mean annual rainfall less than $500 \mathrm{~mm}$ and high mean monthly temperature of between $25^{\circ} \mathrm{C}$ and $30^{\circ} \mathrm{C}$. The Sudanian ecoregion covers extends from South Sudan to West Uganda. It is mainly characterized by a semi-arid and equatorial savanna type of climate with a severe dry season. The highlands and mountain areas of Kenya as well as most of southern and western parts of Uganda with more than $1000 \mathrm{~mm}$ mean annual rainfall in the forest zone are defined as Afromontane. Along the Kenyan,

15 Tanzania and Southern Somalia coastline is the Zanzibar-Inhambane ecoregion, which consists of forests and Mangroves and characterised by mean annual rainfall between 800 and $1200 \mathrm{~mm}$. Most parts of Uganda, and some parts of western Kenya, northern Tanzania and Eastern Congo as well as the whole of Eastern Rwanda and Burundi comprise the Lake Victoria ecoregion, which is characterized by rain forest with semi-evergreen forest and wood- and shrubland as the dominant vegetation. This area receives high and well distributed rainfall.

\section{$20 \quad$ 2.2 LAI Data}

LAI data were sourced from the third generation Global Inventory Monitoring and Modelling Studies LAI (GIMMS LAI3g) dataset to characterize vegetation dynamics for the period spanning 1982 to 2011 . This dataset has a spatial resolution of about $8 \mathrm{~km}$ and 15-day temporal resolution. As described in Zhu et al. (2013), the dataset was produced from the fusion of GIMMS NDVI3g (Pinzon and Tucker, 2014) and an improved version of Moderate Resolution Imaging Spectroradiometer

25 (MODIS) LAI that provides 8-day global LAI data from 2000 to 2009 at $1 \mathrm{~km}$ spatial resolution (Yuan et al., 2011) using a Feed Forward Neural Network (FFNN) algorithm. The MODIS LAI dataset was resampled to the same spatial $(8 \mathrm{~km})$ and temporal (15 day) resolution as the GIMMS NDVI3g and used to train the FFNN algorithm for the overlapping period 2000 to 2004 and to test its predictive capability for the period 2005 to 2009. The GIMMS LAI3g data has been validated using ground based observations measured across East Africa (Pfeifer et al., 2014) and has also been used to study vegetation 30 dynamics at a global scale (Cook and Pau, 2013). 
Hydrol. Earth Syst. Sci. Discuss., doi:10.5194/hess-2016-502, 2016

The biweekly LAI data was smoothed using an optimized Savitzky-Golay (S-G) filter commonly used to correct Earth observation data (Chen et al., 2004) to remove superfluous values. The smoothed biweekly dataset was then aggregated using the maximum value composites (MVC) approach to create monthly LAI time series from 1982 to 2011. The MVC approach obtains monthly values as the maximum value per pixel in each pair of bi-monthly datasets.

\section{$5 \quad 2.3$ Climate data}

The precipitation data was obtained from version 2 of the Climate Hazards group Infrared Precipitation with Stations (CHIRPS) dataset (Funk et al., 2015). The CHIRPS dataset is a $0.05^{\circ}(\sim 5 \mathrm{~km})$ spatial resolution global gridded dataset of monthly precipitation available from 1981 to 2015 and obtained by merging satellite observations, average precipitation from stations, and precipitation predictors such as elevation, latitude and longitude. The data is generated based on an

10 ensemble approach whereby Tropical Rainfall Measuring Mission Multi-satellite Precipitation Analysis version 7 (TMPA 3B42 v7) dataset is used to calibrate global Cold Cloud Duration (CCD) rainfall estimates. The CCD-derived estimates are then merged with World Meteorological Organization's Global Telecommunication System (GTS) gauged data using a 'smart interpolation' approach (Funk et al., 2015). Comparisons with other satellite precipitation estimates and observed rainguage data have shown that this data set provides useful long-term precipitation estimates for Africa (Ceccherini et al.,

15 2015; Dembélé and Zwart, 2016; Toté et al., 2015). In addition, this dataset has been used in the East Africa region previously to provide high resolution and combined gauge-satellite precipitation estimates (Ayana et al., 2016; Pricope et al., 2013). In this study, the precipitation data, in WGS- 84 coordinate system, was resampled to $8 \mathrm{~km}$ using nearest neighbour approach to match the LAI spatial resolution and used to compute the Antecedent Precipitation Index (API) according to Heggen (2001) as shown in (1). API reflects antecedent soil moisture conditions and is therefore appropriate in quantifying

20 land-atmosphere relations.

$$
A P I_{j}=k A P I_{j-1}+P_{j} \quad(\mathbf{1})
$$

Where $A P I_{j}$ is API at month $\mathrm{j}, k$ is a decay constant which generally ranges between 0.80 and 0.98 (Feng et al., 2015; Heggen, 2001), $A P I_{j-1}$ is API in the previous month and $P_{j}$ is the precipitation at month $\mathrm{j}$. In this study the decay constant was set at average value of 0.90 and the initial API value was considered as the average daily precipitation for October to December prior to the study period $1982-2011$.

25 Minimum and maximum temperature data was obtained from a high resolution daily meteorological dataset developed by Princeton university hydrology group for East Africa (Chaney et al., 2014; Sheffield et al., 2006). This dataset was created by downscaling the National Centers for Environmental Prediction-National Center for Atmospheric Research (NCEPNCAR) reanalysis, adjusting for temporal inconsistencies and assimilating quality controlled and gap-filled Global Summary of the Day (GSOD) in situ measurements to remove random errors. The temperature dataset was also resampled to $8 \mathrm{~km}$ spatial resolution at a monthly time-step to correspond to the LAI and precipitation data. 


\subsection{Land cover/use data}

Accurate identification of land cover types is vital for the characterization of vegetation dynamics. The $8 \mathrm{~km}$ spatial resolution AVHRR-based land cover data set with University of Maryland global Land Cover Classification scheme (Hansen et al., 1998) was used in this study.

\section{$5 \quad 3$ Methods}

\subsection{Characterization of Vegetation Dynamics}

The characterization of vegetation dynamics was performed on a pixel by pixel basis. The Theil-Sen median slope method and Mann-Kendall significance test were used for the long term trend analysis and the Hurst exponent was then applied to assess the persistence of vegetation trends. Each of these methods is explained in detail in the following sections.

\section{$10 \quad$ 3.1.1 Long-term trend analysis}

The Thiel-Sen median slope estimator, used in this study, is a non-parametric method widely used in estimating trends to reduce the effects of outliers, tied values and errors in the trend estimate. Its application in vegetation research has shown great potential to identify long-term trends (Fensholt et al., 2012, 2013; Marshall et al., 2012; Teferi et al., 2015). This method computes the slopes between all $n(n-1) / 2$ pair wise combinations in a time series and uses the median slope to

15 characterize the trend in the overall time series. Monthly LAI data was used as opposed to data aggregated to annual means to preserve length of the time series. The significance of the trend was determined using the Mann-Kendall test. This method has been widely used in combination with Thiel-Sen median trend analysis to evaluate the significance of trend in vegetation time series data (Fensholt and Proud, 2012; Marshall et al., 2012; Teferi et al., 2015).

Seasonal variations in LAI data influence the detection of long term trends in the time series analysis. We therefore used

20 standardized anomalies (Z-scores) to remove the seasonality in the LAI dataset for trends and variability analysis (Boschetti et al., 2013; Ceccherini et al., 2014; Teferi et al., 2015). In addition, the sub-annual sampling nature of the time series induces serial autocorrelation, which often leads to an over- or underestimation of the statistical significance of observed trends (Wang et al., 2015; Yue and Wang, 2002). We therefore used the trend-preserving pre-whitening procedure proposed by Yue et al. (2002) to remove the autocorrelation component in the de-seasoned monthly LAI time series based on a lag-

25 one autoregressive model. The computed trends were categorized at the $95 \%$ confidence band, into four types namely; increasing, decreasing and steady $(p \geq 0.05)$ increase and decrease. 


\subsubsection{Persistence of vegetation trend}

The potential future trends in LAI time series data were evaluated by considering whether the long-term variation in the data was random or continuous. The Hurst exponent (H), which was proposed by Hurst (1951) and improved by Mandelbrot and Wallis (1969), has been widely used to evaluate the persistence of trends in time series data. The commonly used approach

5 to compute $\mathrm{H}$ is the rescaled range $(\mathrm{R} / \mathrm{S})$ technique and its application in vegetation time-series analysis is well documented (Jiapaer et al., 2015; Ndayisaba et al., 2016; Tong et al., 2016). The value of $\mathrm{H}$ ranges from 0 to 1 and is typically categorized into three levels $(\mathrm{H}<0.5, \mathrm{H}=0.5$ and $\mathrm{H}>0.5) . \mathrm{H}<0.5$ indicates "anti-persistent behaviour" (or negative autocorrelation) in the time series, meaning trends are likely to revert to their long-term mean. $\mathrm{H}=0.5$ indicates that the time series is a random process and therefore future trends are not correlated with the trend in historical data. $\mathrm{H}>0.5$ indicates a

10 "persistent behaviour" in the long term and therefore historical trends are likely to prevail in the future. Following the approach of Tong et al. (2016), the LAI trends and H values were superimposed and classified as shown in Table 1.

\subsection{Relationship between LAI and climatic variables}

\subsubsection{Temporal correlation analysis}

The vegetation-climate interactions were assessed based on instantaneous and lead/lag correlations as well as a statistical

15 feedback parameter. The standardized datasets were linearly de-trended prior to the correlation analysis and estimation of the feedback parameter. In the correlation analysis, the non-parametric spearman's rho was calculated on a pixel by pixel basis and evaluated at the $95 \%$ significance level. Vegetation-climate interactions are typically non-linear hence the spearman's rho is the most appropriate for assessing their relationships and has been widely used to relate vegetation indices to climate variables (Hamunyela et al., 2013; Zeng et al., 2013). A maximum of three-month lead/lag period was considered in the

20 analysis of climate forcing on vegetation and vice versa.

Conventional lead/lag correlation analysis does not necessarily express vegetation feedback on climate but rather represents qualitatively the characteristics of vegetation-climate interaction (Notaro et al., 2006). A further step was therefore carried out to determine the strength of the vegetation forcing on climate based on a feedback parameter (Liu et al., 2006; Nataro et al., 2008; Notaro, 2008; Zhang et al., 2011). The estimation of the feedback parameter for vegetation influence on

25 atmospheric variables is clearly outlined in Liu et al. (2006). This parameter represents the instantaneous local response of atmosphere to vegetation variations (i.e the fraction of variability in climatic variables attributed to variations in vegetation). It was computed as a ratio of lagged covariance between vegetation and climate to lagged covariance of vegetation based on monthly data as shown in (2).

$$
\lambda_{A}=\frac{\operatorname{Cov}(V(t-\tau), A(t))}{\operatorname{Cov}(V(t-\tau), V(t))}
$$


Where $\lambda_{A}$ is the feedback parameter or efficiency, $V$ is LAI, $A$ is climate variable (API or temperature) and $\tau$ is the time lag. Upto three month lags were used and the feedback parameter was computed as the weighted average from the three lags using weights of 1.0, 0.5 and 0.25 for lags 1, 2 and 3, respectively. Following Notaro et al. (2006), the statistical significance of the feedback parameters was assessed using the Monte Carlo bootstrap approach in which $\lambda_{A}$ was repeatedly computed

51000 times based on random permutations of the climate time series and the original LAI time series at each grid point. The cumulative probability produced was then used to judge the significance of the original $\lambda_{A}$ in terms of the percentage of permutation-based parameters at least as extreme as the original $\lambda_{A}$. Significant positive (negative) $\lambda_{A}$ signifies a significant positive (negative) forcing of LAI on the climatic variable.

\subsubsection{Spatial regression analysis}

10 Spatial variability in the LAI-climate relationship was explored using Geographically Weighted Regression (GWR) and spatial regression analysis. For this analysis, the monthly LAI, API, Tmin and Tmax time series was aggregated to seasonal quantiles for the DJF (December - February) and MAM (March - May) seasons. A random sample encapsulating $25 \%$ of the total pixels was then selected after removing NoData cases resulting to a total of 7,179 data points. A total of four models, shown below as I-IV, were formulated to explore the spatially variable relationship between LAI, API and temperature.

$$
\begin{aligned}
& \text { I: } \quad L A I_{M A M}=A P I_{D J F}+A P I_{M A M}+T M I N_{D J F}+T M I N_{M A M}+T M A X_{M A M} \\
& \text { II: } L A I_{M A M}=A P I_{M A M}+T M I N_{M A M}+T M A X_{M A M} \\
& \text { III: } A P I_{M A M}=L A I_{D J F}+L A I_{M A M}+T M I N_{D J F}+T M I N_{M A M}+T M A X_{M A M} \\
& \text { IV: } A P I_{M A M}=L A I_{D J F}+L A I_{M A M}+A P I_{D J F}+T M I N_{D J F}+T M I N_{M A M}+T M A X_{M A M}
\end{aligned}
$$

An OLS model is based on the assumption that the derived parameters apply globally over a region of study with no

20 consideration of the location of specific sites from which measurements were observed. However, a multiplicity of studies has shown that vegetation-climate relationships vary spatially in both the magnitude and sign of model parameters. Consequently, a local model such as GWR is deemed appropriate to account for spatial non-stationarity in the vegetationclimate relationship (Fotheringham et al., 2002). The GWR method and underlying principles is widely documented (Foody, 2003; Fotheringham et al., 2002; Kang et al., 2014; Zhao et al., 2014). In summary, GWR extends the conventional global

25 OLS by including geographical location parameter for the coefficients as shown in (3).

$$
y_{i}=\beta_{0}\left(u_{i}, v_{i}\right)+\sum_{k} \beta_{k}\left(u_{i}, v_{i}\right) x_{i k}+\varepsilon_{i}
$$

Where $\left(u_{i}, v_{i}\right)$ denotes a vector of coordinates of the point $i$ at which the parameters are to be estimated, $\beta_{0}\left(u_{i}, v_{i}\right)$ is the intercept, and $\beta_{k}\left(u_{i}, v_{i}\right)$ is the local parameter estimate for independent variable $x_{i k}$, while $\varepsilon_{i}$ is the random error term residual at the same location, which is assumed to be randomly distributed. The $\beta_{0}$ and $\beta_{k}$ parameters (i.e intercept and slope, respectively) in (3) are estimated based on a spatial weighting approach which involves a user-defined spatial kernel (fixed or adaptive) which is characterized by a geometric shape (square or circle), bandwidth (the rate at which a given point is 
influenced by neighbouring points), and a functional formulation (gaussian, exponential, bi-square) (Fotheringham et al., 2002). In a matrix form, these parameters can be estimated as:

$$
\hat{\beta}\left(u_{i}, v_{i}\right)=\left(X^{T} W\left(u_{i}, v_{i}\right) X\right)^{-1} X^{T} W\left(u_{i}, v_{i}\right) Y
$$

Where $\hat{\beta}\left(u_{i}, v_{i}\right)$ represents the unbiased estimate of the regression coefficient at a given location while $W\left(u_{i}, v_{i}\right)$ is the weighting matrix which guarantees that observation near to the specific location has more influence on the analysis, and $X$

5 and $Y$ are matrices for independent and dependent variables, respectively. Unlike autoregressive models and geostatistical methods which use additional regression term and variogram, respectively, to represent spatial dependence, GWR incorporates spatial dependence in each of the local regression equations. An adaptive bi-square function was used to specify the weights in this study. The optimum bandwidth $(b)$ is a critical issue in the GWR analysis as it contributes to decrease of bias in models. Although smaller bandwidths produce parameter estimates with lower bias, these estimates are also

10 characterized by large standard errors due to a small number of samples used to calibrate each locally weighted regression. To establish the optimum $b$, we used the corrected Akaike information criterion $\left(A I C_{c}\right)$ (Hurvich and Tsai, 1989; Kang et al., 2014; Zhao et al., 2014). The GWR analysis was further compared to Ordinary Least Squares (OLS) regression analysis using AICc, coefficient of determination $\left(\mathrm{R}^{2}\right)$ and sigma ${ }^{2}$. In addition, global and local Moran indexes (Moran's I) were used to assess presence of spatial autocorrelation in the residuals of the models. The Moran's I has an expected value near zero for

15 a large number of samples under the null hypothesis that no spatial autocorrelations exist among variables. Positive and negative autocorrelations are indicated by positive and negative values.

\section{Results}

\subsection{Temporal trend in LAI}

The three trend types namely increasing, decreasing and stable $(p \leq 0.05)$ accounted for $13 \%, 3 \%$ and $84 \%$ respectively, of 20 the total vegetated area in the region. Areas with significant increasing and decreasing trend at the $95 \%$ confidence level are shown in Figure 2a. Northern Kenya shows significant negative trends mainly in Marsabit national park and reserve, and Turbi forest areas. Small patches of Tsavo national park also exhibit significant decreases in LAI. Increasing trends are more prevalent in northern Uganda, a region characterized by woodlands and wooded grasslands. Increasing trends are also evident in many cropped areas of Rwanda and Burundi and southern parts of Tanzania, particularly in Selous game reserve

25 and Ruaha national park. The distribution of the magnitude of significant trends over different land cover types is shown in Figure $2 b$. The mean LAI trend in evergreen broadleaf forest, deciduous broadleaf forest and cropland classes was mainly positive while open and closed shrubland showed decreasing trends. 


\subsubsection{Persistence of vegetation trends}

Across the region, values of $\mathrm{H}$ ranged between 0.41 and 0.98 with a mean of 0.6 which implies wide-spread sustainability in the LAI trends in the region. The areas with persistent LAI trends $(\mathrm{H}>0.5)$ accounted for $99.8 \%$ of the total vegetated area, indicating that most vegetation cover in the region is likely to maintain historical trends. The anti-persistent areas account for

5 a small proportion $(0.2 \%)$ of the study region. Although mean $\mathrm{H}$ values across different land cover types were relatively similar, high values were prevalent in deciduous broadleaf forest, open shrubland and croplands, while low levels of persistence were prevalent in woodlands, grassland and evergreen broadleaf forest.

The LAI trend and $\mathrm{H}$ values were combined into six classes (Table 1) to show potential future vegetation trends in the region as shown in Figure 3. Areas with high $\mathrm{H}$ values correspond to areas with high significant positive and negative LAI trends.

10 Sustained and steady development $(\mathrm{H}>0.5$ and $p \geq 0.05)$ accounted for most of the study region $(84.1 \%)$ of which sustained and steady positive (SSP) and negative (SSND) changes were indicated in $51.9 \%$ and $32.2 \%$ of the study region, respectively. All the pixels with anti-persistent trends $(\mathrm{H}<0.5)$ also indicated insignificant LAI trends $(p \geq 0.05)$ and were therefore categorized as undetermined development areas (UD, $0.2 \%$ of the study region).

\subsection{Vegetation-climate temporal correlation analysis}

\section{$15 \quad 4.2 .1$ Instantaneous correlation}

The instantaneous correlations (shown in Figure 4) were stronger for API compared to temperature. Most of the region indicates significant positive correlations with API. Across the western parts of the region, LAI is moderately but significantly and positively correlated with API. The majority of Kenya and Northern Tanzania showed a strong positive correlation with API. These areas are mainly characterized by woodlands and grasslands. This reflects a strong sensitivity of vegetation to rainfall in these areas. Temperature was mainly negatively correlated with LAI in the region.

\subsubsection{Correlations with leading climatic variables}

A lag-time effect in the climate forcing on vegetation was evident and it varied across the region. API, minimum and maximum temperature showed more than one month lags in $8.9 \%, 54.7 \%$ and $36.9 \%$ of the significantly $(p<0.05)$ correlated areas, respectively. Delayed response to minimum temperature was prevalent in woodlands and grasslands while delayed

25 response to maximum temperature was more prevalent in woodlands, grasslands and closed shrublands. Across all the landcover types, there was a high rate of delayed response to API but was mostly prevalent in woodlands.

The spatial distribution of the maximum significant correlations between LAI and API, Tmin and Tmax, with the climatic variables leading by one to three months, is shown in Figure 5. Although API showed a more instantaneous relationship with LAI, the API-lead correlations were also positive and highly significant emphasizing the predominance of precipitation 

API in $4.4 \%$ ( $\rho=-0.38$ to -0.11$)$ of the vegetation-covered area. Significant positive correlation between LAI and API was exhibited in $79.6 \%$ ( $\rho=0.11$ to 0.72$)$ of the area. Leading maximum temperature exhibited a stronger negative forcing on vegetation when compared to minimum temperature. On the other hand, $12.2 \%$ and $17.1 \%$ of the area exhibited positive ( $\rho=$

50.10 to 0.30 ) and negative ( $\rho=-0.31$ to -0.10 ) correlations with minimum temperature respectively while $2.8 \%$ and $54.0 \%$ of the area exhibited positive $(\rho=0.10$ to 0.27$)$ and negative $(\rho=-0.54$ to -0.00$)$ correlations with maximum temperature respectively. Regarding API, the correlation coefficient was higher for positive correlation than for negative correlation. This shows that LAI variations in the region are more sensitive to precipitation with a generally positive correlation. The results from correlation analysis with leading climatic variables indicate a possibility to predict vegetation dynamics using

10 API, particularly in water limited areas of Eat Africa.

The influence of vegetation type on the correlations between LAI and leading climatic variables were also examined. Figure 6 shows the distribution of correlation in different landcover types with leading API, Tmin and Tmax at the 95\% confidence. Regarding Tmax, mean correlation across the land cover classes is mainly negative while Tmin show somewhat equal distribution of negative and positive correlations across the landcover types.

\section{$15 \quad$ 4.2.3 Correlations with leading LAI}

Correlations with LAI leading can be used to qualitatively infer vegetation influence on climate. LAI-leading correlation analysis showed that vegetation exerted varied significant influence on both temperature and API. Figure 7 shows the spatial distribution of the vegetation influence on API and temperature while Figure 8 shows the significant correlations for each land cover type. Overall, the influence on API was more significant compared to temperature. Compared to leading climate correlations, leading LAI present more widespread positive significant correlations indicating more significant positive vegetation forcing on climate. The results also indicate a lower sensitivity of Tmin to vegetation with positive correlations mainly exhibited in areas with significant increasing vegetation. In contrast, a large spatial extent shows significant correlation between leading-LAI and Tmax, somewhat equally composed of negative and positive correlation. The prevalence of positive (for API) and negative (for temperature) correlations suggest corresponding positive and negative influence on API and temperature by vegetation, respectively.

\subsubsection{Strength of vegetation feedback on climate}

Figure 9 shows the feedback parameters for API, Tmin and Tmax. Consistent with the correlation analysis with leading LAI (Figure 7), vegetation feedback on API is statistically significant at $95 \%$ level in most parts of the region as also found by Liu et al. (2006). Across the study period, stronger vegetation feedback was found with API than temperature. In addition,

30 the feedback was stronger for Tmin than Tmax which is in contrast with results obtained by Wi et al. (2011) over China. For Tmin, negative feedbacks dominate with a moderate areal extent achieving a significance level of $p<0.05$. Across the region, vegetation exhibits an asymmetric influence on Tmax and Tmin. Smaller and less significant effects on Tmax are exhibited 
Hydrol. Earth Syst. Sci. Discuss., doi:10.5194/hess-2016-502, 2016 Tmin and Tmax to the diurnal asymmetry in its forcing on the surface energy balance. Significant positive vegetation effects on Tmin and Tmax were shown in areas of southern Tanzania which corresponds with regions with significant positive LAI trends, as well as significant positive correlations between leading LAI with Tmin and Tmax. This may have been achieved

5 due to larger positive effects of decrease in surface albedo due to increase in LAI (thus increased solar heating) than the negative effects of increased evaporative cooling from increased vegetation in those areas (Zhang et al., 2009).

\subsection{The spatial patterns of LAI-climate relationships}

\subsubsection{Model performance}

Table 2 shows the performance of different models as well as results of the auto-correlation test on the residuals of each

10 model. The model accuracy and precision statistics are in terms of AICc, $\mathrm{R}^{2}$, sigma ${ }^{2}$, Moran's I. Generally, GWR showed better performance compared to OLS. All models achieved an adjusted $\mathrm{R}^{2}$ over 0.7 , except OLS models I and II which achieved adjusted $\mathrm{R}^{2}$ values of 0.68 and 0.59 , respectively. In addition, these models (OLS models I and II) achieved significantly high Moran's I on regression residuals ( 0.53 and 0.63 , respectively), indicating that they were mis-specified. With LAI as the dependent variable (models I and II), the GWR model produced more accurate simulations in all cases as 15 shown by higher $\mathrm{R}^{2}$ values, lower AICc, sigma ${ }^{2}$ and Moran's I values compared to the OLS models. With API as the dependent variable (models III and IV), the GWR model IV was the best with $1 \mathrm{R}^{2}$ compared to 0.97 for OLS. The AICc for this model was 9086 and 29926.90, while the Sigma ${ }^{2}$ was 0.34 and 1.94 for GWR and OLS, respectively. As indicated by the $\mathrm{R}^{2}$ values, the explanatory variables in the GWR in model III could explain upto $98 \%$ of the variance in API. Detailed descriptive statistics of the parameters for models I and IV for both OLS and GWR are shown in Table 3 while the

20 improvements in GWR are compared to OLS analysis for models I and IV as shown in Table 4. The inclusion of DJF API as a predictor in model IV significantly improved the predictability of MAM API showing that the moisture condition in the region during the long-rains season can be significantly influenced by the moisture levels during the preceding dry season across the region. However, this led to an increase in Moran's I statistic which shows that a more significant spatial structure exists in the residuals.

\section{4.3.2 Spatial dependence in the relationships between LAI and climatic factors}

The relationship between LAI and climatic variables showed significant spatial heterogeneity as indicated by a wide range of local regression coefficients (Table 3). According to Fotheringham et al. (2002), parameter non-stationarity is evident when the inter-quartile range of local parameter estimates is greater than the \pm 1 standard deviation of the equivalent OLS parameter estimate. As shown in Table 3, all the inter-quartile ranges of estimated local parameters in model I fall outside

30 the \pm 1 standard deviation of equivalent OLS parameters. The OLS estimates for the parameters of API $I_{M A M}, T_{M I N}$ DJF and $\mathrm{TMAX}_{\mathrm{MAM}}$ are within the $25 \%$ quartile and median range indicating that most of the GWR estimates for these variables were 
much higher. Global parameter estimates for $\mathrm{TMIN}_{\mathrm{MAM}}$ and $\mathrm{API}_{\mathrm{DJF}}$ in this model are within median and $75 \%$ percentile range of local estimates. These estimates imply that the relationship between LAI and the climatic variables is spatially nonstationary. In model IV, the global parameter estimate for $\mathrm{TMIN}_{\mathrm{DJF}}$ is greater than the $75 \%$ percentile of the local estimate indicating that most of the estimates in the GWR are lower than the OLS estimate while the global estimate for TMAX MAM

5 lower than $25 \%$ percentile of the local estimate. As indicated by high positive coefficient, API $_{\text {DJF }}$ was the most important exploratory factor in MAM API in both local and global regression analysis. TMAX $\mathrm{DJF}_{\mathrm{F}}$ was not a significant explanatory for both LAI and API hence was not considered in both the local and global regression analysis.

Residual autocorrelation is a key manifestation of spatial dependence between pairs of point-referenced observations at a given spatio-temporal distance apart hence it is commonly used as a model diagnostic measure and is predominantly

10 expressed in terms of Moran's I statistic. The spatial correlograms for the residuals of models I and IV under OLS and GWR are shown in Figure 10. The GWR correlograms indicate significant negative Moran's I values for the first lag while the other values are significantly low in both models. In the OLS models, residuals up to lag 6 in model I and 9 in model IV are significantly and positively auto-correlated. This confirms the superiority of GWR in addressing spatially auto-correlated error terms compared to OLS analysis.

\section{Discussion}

The expanding archive of timely and high spatial resolution satellite earth observations offers prospects for the assessment of regional dynamics of land surface variables. The current analyses and results supports the evidence that East Africa has been characterized by geographically extensive patterns of varied vegetation dynamics (also found by a number of studies e.g Hoscilo et al., 2015; Landmann and Dubovyk, 2013; Pricope et al., 2013). The results presented here, which to a large

20 extend correspond with the findings of Hoscilo et al. (2015), also provide a view of vegetation dynamics that could be used to fully appreciate where significant changes have occurred in the region. In Northern Uganda and southern parts of Tanzania, persistently increasing LAI trends were found which indicates continued increasing trends in the future. The predominant sustained and positive LAI trends found in the region give a positive picture on regional sustainability of vegetation cover. The significant and persistent negative trends in north-central and southern Kenya coincide with significant

25 decline in precipitation and can be attributed to climatic effects as also reported by Hoscilo et al. (2015). The pattern of consistently declining vegetation extending from Southern Ethiopia, through central Kenya into central Tanzania (an area categorized as a pastoral zone) was also reported by Pricope et al. (2013) based on NDVI data over 1982-2011 period. They also reported an alarming decline in shrub and potential expansion of grass- and cropland in those areas between 2001-2003 and 2007-2009. Thus the decline in LAI in our analysis could be a combined effect of climate as well as replacement of

30 shrubs by grass and crops with lower LAI values.

Both instantaneous and lead/lag correlations between anomalies of LAI and API and temperature were also assessed over East Africa. The lead/lag climate/LAI correlation analysis is vital in inferring qualitative characteristic of large- scale 
vegetation-climate interaction. It is well accepted that the trajectory of vegetation dynamics is mainly a function of climaterelated factors which determine vegetation growing conditions (Gao et al., 2016; Nemani et al., 2003; Wu et al., 2015), and human activities which alter the seasonal and gradual changes in vegetation (Pfeifer et al., 2013). In addition, time lags which varied across different biomes in the vegetation response to climatic factors was found as also observed in previous

5 studies (Wu et al., 2015). We primarily focused on vegetation response to climatic factors thus impacts of human activities were not quantified. The distribution of correlation between LAI and climate factors not only relate to spatial variation in climatic variables, but also the distinctive spatial vegetation heterogeneity in the region which may create some uncertainties in the climate forcing on vegetation. The slow variance of LAI is exceeded by the large internal atmospheric variability thus instantaneous correlations show mainly the vegetation response to climatic variables. However, some of vegetation feedback

10 on climate may also be encapsulated in the instantaneous correlations (Notaro et al., 2006). In the arid and semi-arid areas in the region, temperature exceeds the minimum required for vegetation growth but moisture is limited, thus vegetation activity is mainly sensitive to drought stress. In addition, the fast response to precipitation is attributable to the land cover in these areas which is mainly composed of grasses and shrubs. Areas with significant positive LAI-API instant correlation were dominant indicating the vital role of soil moisture in vegetation dynamics in the region.

15 The leading climate correlations show widespread significant negative correlation with Tmax compared to Tmin while API shows mainly positive correlation. This emphasizes on the predominant precipitation forcing on vegetation in the region which is consistent with findings of Alessandri and Navarra (2008). It is also clear that areas with significant LAI trends do not show significant instantaneous correlations with API but show significant negative correlation with leading API which implies increased green up during the dry season. These areas are mainly composed of forest cover thus our results are

20 consistent with finding in other studies which attributed the decline in vegetation activity to a decrease in solar radiation and temperature as a result of cloud cover during the wet season (Brando et al., 2010; Hilker et al., 2014; Hutyra et al., 2007; Samanta et al., 2012). Spatial extent of the negatively correlated areas with leading API increase with longer time lags. Due to the expected growth in greenhouse gas concentrations, Cook and Vizy (2012) projected severe decreases in the number of growing-season days in East Africa by the mid-twenty-first century. In addition, Cook and Vizy (2013) analysed the

25 associated declines in rainfall during the growing season and found 1-2 $\mathrm{mm}_{\text {day }}{ }^{-1}$ decrease in precipitation rates in southern Kenya and Tanzania in $21^{\text {st }}$ Century compared to $20^{\text {th }}$ Century simulation, which they associated with anomalous moisture transport and divergence in the overlying layer responsible for transporting moisture away from the region and into the Congo basin. Adhikari et al. (2015) reported that the expected increase in Tmin and Tmax in the region ranges from $1.4^{\circ} \mathrm{C}$ to $5.5^{\circ} \mathrm{C}$ by $2090 \mathrm{~s}$. Although these and many more studies have highlighted inherent uncertainties in their findings, the 30 projected climate changes in the region are likely to exert even stronger influence on vegetation dynamics in the region. Correlations with leading LAI show significant vegetation forcing on precipitation in the region, also reported by Alessandri and Navarra (2008). Significant positive vegetation forcing on Tmin and Tmax is indicated in areas with significant LAI trends. Most parts of Kenya and central Tanzania show significant positive feedback on API. Although Tmax shows significant correlation with leading LAI in larger spatial extent compared to Tmin, the spatial extent of significant feedback 

decreasing LAI trends in the region. The regions with significant positive feedback on Tmin and Tmax in southern Tanzania also correspond with significant positive correlations and significant positive LAI trends. The significant high positive vegetation feedback on precipitation shown in Figure 9 is partly due to the fast vegetation response to API in the arid and

5 semi-arid areas (Figure 5) mainly characterized by shrubs and grasses (Liu et al., 2006). Generally, the areas with negative feedback on Tmin and Tmax correspond with significant negative LAI and API trends in the arid and semiarid areas in the region. Based on findings of Zhou et al. (2007), decrease in vegetation cover and soil wetness is likely to increase Tmin and thus reduce diurnal temperature range over semi-arid regions such as northern Kenya. The GWR analysis shows the significance of non-local effects in the analysis of relationships between LAI and climatic variables. Based on the coefficient

10 values in GWR, API and Tmin showed higher influence on LAI as also shown in the correlation analysis.

The findings of this study together with those of other studies indicate the value of vegetation-atmosphere interactions for enhanced understanding of the vegetation impacts on land-atmosphere coupling. However, there is need to further shed light on the indirect physical mechanisms in the vegetation forcing on climatic variables in the region based on process based approaches. In addition, remote vegetation and oceanic forcing should be considered to fully attribute vegetation influence

15 on land-atmosphere coupling in the region. It is also worth noting that higher resolution LAI and climatic data might present significantly varying results since a large proportion of the study area is mainly arid and semi-arid thus at $8 \mathrm{~km}$ spatial resolution the actual LAI dynamics may not be well capture.

\section{Conclusions}

This paper focused on understanding the spatial-temporal variations in LAI during 1982-2011 period over East Africa based

20 on robust non-parametric trend tests. In addition, lead/lag correlations between LAI and API, Tmin and Tmax from observations were estimated. Local vegetation forcing on climatic variables was also analysed based a statistical method which isolates vegetation feedback on climatic variables from the atmospheric noise. We find hotspots with significant LAI declines over the last 30 years thus signifying areas of potential land degradation and increased vulnerability to climate change in the future. Although potential climatic degradation has been cited in these areas, other factors such as population pressures and declining land health should be considered in future studies in the region. The region is mainly characterized by sparse vegetation mainly composed of grass and shrubs thus at the $8 \mathrm{~km}$ spatial resolution used in this study, some gradual and abrupt vegetation changes may be masked. We therefore recommend further analysis at higher spatial resolution. The vegetation-climate correlation and regression analysis successively provided a qualitative view of the interactions between vegetation and climate. The feedback parameter provided a simple approach for estimating the strength of

30 vegetation forcing on the climatic variables, albeit it's inherent limitations. However, the results will strongly benefit from consideration of other indirect physical mechanism influencing the land-atmosphere coupling. This can easily be achieved 
through use of well parameterized land-atmosphere coupled models solving both the land surface water and energy balance in a coupled manner. Future interests in this region should therefore attempt to exploit different pathways in the landatmosphere feedbacks for enhanced predictability of the direction and magnitude of the land surface feedbacks.

5 Acknowledgment: This work was supported primarily by the CGIAR research program on Forest, Trees, and Agroforestry under the project, titled: Earth Observation Based Assessment of the Water Balance in East Africa.

\section{References}

Adhikari, U., Nejadhashemi, A. P. and Woznicki, S. A.: Climate change and eastern Africa: a review of impact on major crops, Food Energy Secur., 4(2), 110-132, doi:10.1002/fes3.61, 2015.

10 Alessandri, A. and Navarra, A.: On the coupling between vegetation and rainfall inter-annual anomalies: Possible contributions to seasonal rainfall predictability over land areas, Geophys. Res. Lett., 35(2), 1-6, doi:10.1029/2007GL032415, 2008.

Arora, V. K.: Modelling vegetation as a dynamic component in soil-vegetation-atmosphere-transfer schemes and hydrological models, J. Geophys. Res., 40(2), 1006, doi:10.1029/2001RG000103, 2002.

15 Ayana, E. K., Ceccato, P., Fisher, J. R. B. and DeFries, R.: Examining the relationship between environmental factors and conflict in pastoralist areas of East Africa, Sci. Total Environ., 557-558, 601-611, doi:10.1016/j.scitotenv.2016.03.102, 2016.

Bao, G., Qin, Z., Bao, Y., Zhou, Y., Li, W. and Sanjjav, A.: NDVI-Based Long-Term Vegetation Dynamics and Its Response to Climatic Change in the Mongolian Plateau, Remote Sens., 6(9), 8337-8358, doi:10.3390/rs6098337, 2014.

20 Bobée, C., Ottlé, C., Maignan, F., de Noblet-Ducoudré, N., Maugis, P., Lézine, a.-M. and Ndiaye, M.: Analysis of vegetation seasonality in Sahelian environments using MODIS LAI, in association with land cover and rainfall, J. Arid Environ., 84, 38-50, doi:10.1016/j.jaridenv.2012.03.005, 2012.

Boschetti, M., Nutini, F., Brivio, P. A., Bartholomé, E., Stroppiana, D. and Hoscilo, A.: Identification of environmental anomaly hot spots in West Africa from time series of NDVI and rainfall, ISPRS J. Photogramm. Remote Sens., 78, 26-40,

25 doi:10.1016/j.isprsjprs.2013.01.003, 2013.

Brando, P. M., Goetz, S. J., Baccini, A., Nepstad, D. C., Beck, P. S. A. and Christman, M. C.: Seasonal and interannual variability of climate and vegetation indices across the Amazon, Proc. Natl. Acad. Sci., 107(33), 14685-14690, doi:10.1073/pnas.0908741107, 2010.

Brink, A. B., Bodart, C., Brodsky, L., Defourney, P., Ernst, C., Donney, F., Lupi, A. and Tuckova, K.: Anthropogenic 30 pressure in East Africa-Monitoring 20 years of land cover changes by means of medium resolution satellite data, Int. J. Appl. Earth Obs. Geoinf., 28(1), 60-69, doi:10.1016/j.jag.2013.11.006, 2014.

Ceccherini, G., Gobron, N. and Migliavacca, M.: On the Response of European Vegetation Phenology to Hydroclimatic 
Hydrol. Earth Syst. Sci. Discuss., doi:10.5194/hess-2016-502, 2016

Anomalies, Remote Sens., 6(4), 3143-3169, doi:10.3390/rs6043143, 2014.

Ceccherini, G., Ameztoy, I., Hernández, C. P. R. and Moreno, C. C.: High-resolution precipitation datasets in South America and West Africa based on satellite-derived rainfall, enhanced vegetation index and digital elevation model., 2015.

Chaney, N. W., Sheffield, J., Villarini, G. and Wood, E. F.: Development of a high-resolution gridded daily meteorological

5 dataset over sub-Saharan Africa: Spatial analysis of trends in climate extremes, J. Climate, 27(15), 5815-5835, doi:10.1175/JCLI-D-13-00423.1, 2014.

Chen, J., Jönsson, P., Tamura, M., Gu, Z., Matsushita, B. and Eklundh, L.: A simple method for reconstructing a highquality NDVI time-series data set based on the Savitzky-Golay filter, Remote Sens. Environ., 91(3-4), 332-344, doi:10.1016/j.rse.2004.03.014, 2004.

10 Cook, B. I. and Pau, S.: A global assessment of long-term greening and browning trends in pasture lands using the GIMMS LAI3g dataset, Remote Sens., 5(5), 2492-2512, doi:10.3390/rs5052492, 2013.

Cook, K. H. and Vizy, E. K.: Impact of climate change on mid-twenty-first century growing seasons in Africa, Clim. Dyn., 39(12), 2937-2955, doi:10.1007/s00382-012-1324-1, 2012.

Cook, K. H. and Vizy, E. K.: Projected changes in east african rainy seasons, J. Climate, 26(16), 5931-5948,

15 doi:10.1175/JCLI-D-12-00455.1, 2013.

Delire, C., de Noblet-Ducoudré, N., Sima, A. and Gouirand, I.: Vegetation dynamics enhancing long-term climate variability confirmed by two models, J. Climate, 24(9), 2238-2257, doi:10.1175/2010JCLI3664.1, 2011.

Dembélé, M. and Zwart, S. J.: Evaluation and comparison of satellite-based rainfall products in Burkina Faso, West Africa, Int. J. Remote Sens., 37(17), 3995-4014, doi:10.1080/01431161.2016.1207258, 2016.

20 Feng, Q., Guo, X., Zhao, W., Qiu, Y. and Zhang, X.: A Comparative Analysis of Runoff and Soil Loss Characteristics between "Extreme Precipitation Year" and "Normal Precipitation Year" at the Plot Scale: A Case Study in the Loess Plateau in China, Water, 7(7), 3343-3366, doi:10.3390/w7073343, 2015.

Fensholt, R. and Proud, S. R.: Evaluation of Earth Observation based global long term vegetation trends - Comparing GIMMS and MODIS global NDVI time series, Remote Sens. Environ., 119, 131-147, doi:10.1016/j.rse.2011.12.015, 2012.

25 Fensholt, R., Langanke, T., Rasmussen, K., Reenberg, A., Prince, S. D., Tucker, C., Scholes, R. J., Le, Q. B., Bondeau, A., Eastman, R., Epstein, H., Gaughan, A. E., Hellden, U., Mbow, C., Olsson, L., Paruelo, J., Schweitzer, C., Seaquist, J. and Wessels, K.: Greenness in semi-arid areas across the globe 1981-2007 - an Earth Observing Satellite based analysis of trends and drivers, Remote Sens. Environ., 121, 144-158, doi:10.1016/j.rse.2012.01.017, 2012.

Fensholt, R., Rasmussen, K., Kaspersen, P., Huber, S., Horion, S. and Swinnen, E.: Assessing Land Degradation/Recovery

30 in the African Sahel from Long-Term Earth Observation Based Primary Productivity and Precipitation Relationships, Remote Sens., 5(2), 664-686, doi:10.3390/rs5020664, 2013.

Foody, G. M.: Geographical weighting as a further refinement to regression modelling: An example focused on the NDVIrainfall relationship, Remote Sens. Environ., 88(3), 283-293, doi:10.1016/j.rse.2003.08.004, 2003.

Ford, T. W. and Quiring, S. M.: Influence of MODIS-Derived Dynamic Vegetation on VIC-Simulated Soil Moisture in 
Hydrol. Earth Syst. Sci. Discuss., doi:10.5194/hess-2016-502, 2016

Oklahoma, J. Hydrometeorol., 14(2007), 1910-1921, doi:10.1175/JHM-D-13-037.1, 2013.

Fotheringham, A. S., Brunsdon, C. and Charlton, M.: Geographically Weighted Regression: The Analysis of Spatially Varying Relationships., Chichester: Wiley., 2002.

Frankignoul, C. and Hasselmann, K.: Stochastic climate models, Part II Application to sea-surface temperature anomalies

5 and thermocline variability, Tellus, 29(4), 289-305, doi:10.1111/j.2153-3490.1977.tb00740.x, 1977.

Funk, C., Peterson, P., Landsfeld, M., Pedreros, D., Verdin, J., Shukla, S., Husak, G., Rowland, J., Harrison, L., Hoell, A. and Michaelsen, J.: The climate hazards infrared precipitation with stations - a new environmental record for monitoring extremes, Sci. Data, 2, 150066, doi:10.1038/sdata.2015.66, 2015.

Gao, Q., Zhu, W., Schwartz, M. W., Ganjurjav, H., Wan, Y., Qin, X., Ma, X., Williamson, M. A. and Li, Y.: Climatic

10 change controls productivity variation in global grasslands, Sci. Rep., 6(26958), doi:10.1038/srep26958, 2016.

Ge, Q., Zhang, X. and Zheng, J.: Simulated effects of vegetation increase/decrease on temperature changes from 1982 to 2000 across the Eastern China, Int. J. Climatol., 34(1), 187-196, doi:10.1002/joc.3677, 2014.

Grace, K., Husak, G. and Bogle, S.: Estimating agricultural production in marginal and food insecure areas in Kenya using very high resolution remotely sensed imagery, Appl. Geogr., 55, 257-265, doi:10.1016/j.apgeog.2014.08.014, 2014.

15 Hales, K., Neelin, J. D. and Zeng, N.: Interaction of vegetation and atmospheric dynamical mechanisms in the mid-Holocene African monsoon, J. Climate, 19(16), 4105-4120, doi:10.1175/JCLI3833.1, 2006.

Hamunyela, E., Verbesselt, J., Roerink, G. and Herold, M.: Trends in Spring Phenology of Western European Deciduous Forests, Remote Sens., 5(12), 6159-6179, doi:10.3390/rs5126159, 2013.

Hansen, M., DeFries, R., Townshend, J. R. G. and Sohlberg, R.: UMD Global Land Cover Classification, 1 Kilometer, 1.0,

20 Department of Geography, University of Maryland, College Park, Maryland, 1981-1994., 1998.

Heggen, R. J.: Normalized Antecedent Precipitation Index, J. Hydrol. Eng., 10.1061/(A, 377-381, 2001.

Hilker, T., Lyapustin, A. I., Tucker, C. J., Hall, F. G., Myneni, R. B., Wang, Y., Bi, J., Mendes de Moura, Y. and Sellers, P. J.: Vegetation dynamics and rainfall sensitivity of the Amazon, Proc. Natl. Acad. Sci., 111(45), 16041-16046, doi:10.1073/pnas.1404870111, 2014.

25 Hoscilo, A., Balzter, H., Bartholomé, E., Boschetti, M., Brivio, P. A., Brink, A., Clerici, M. and Pekel, J. F.: A conceptual model for assessing rainfall and vegetation trends in sub-Saharan Africa from satellite data, Int. J. Climatol., 35(12), 35823592, doi:10.1002/joc.4231, 2015.

Hu, Z., Yu, G., Zhou, Y., Sun, X., Li, Y., Shi, P., Wang, Y., Song, X., Zheng, Z., Zhang, L. and Li, S.: Partitioning of evapotranspiration and its controls in four grassland ecosystems: Application of a two-source model, Agric. For. Meteorol.,

30 149(9), 1410-1420, doi:10.1016/j.agrformet.2009.03.014, 2009.

Hurst, H. E.: Long-term storage capacity of reservoirs, Trans. Amer. Soc. Civ. Eng, 116, 770-808, 1951.

Hurvich, C. M. and Tsai, C.-L.: Regression and time series model selection in small samples, Biometrika, 76(2), 297-307, doi:10.1093/biomet/76.2.297, 1989.

Hutyra, L. R., Munger, J. W., Saleska, S. R., Gottlieb, E., Daube, B. C., Dunn, A. L., Amaral, D. F., de Camargo, P. B. and 
Hydrol. Earth Syst. Sci. Discuss., doi:10.5194/hess-2016-502, 2016

Wofsy, S. C.: Seasonal controls on the exchange of carbon and water in an Amazonian rain forest, J. Geophys. Res. Biogeosciences, 112(3), 1-16, doi:10.1029/2006JG000365, 2007.

Jacobson, A., Dhanota, J., Godfrey, J., Jacobson, H., Rossman, Z., Stanish, A., Walker, H. and Riggio, J.: A novel approach to mapping land conversion using Google Earth with an application to East Africa, Environ. Model. Softw., 72, 1-9,

5 doi:10.1016/j.envsoft.2015.06.011, 2015.

Jiapaer, G., Liang, S., Yi, Q. and Liu, J.: Vegetation dynamics and responses to recent climate change in Xinjiang using leaf area index as an indicator, Ecol. Indic., 58, 64-76, doi:10.1016/j.ecolind.2015.05.036, 2015.

Julien, Y. and Sobrino, J. a.: Global land surface phenology trends from GIMMS database, Int. J. Remote Sens., 30(13), 3495-3513, doi:10.1080/01431160802562255, 2009.

10 Kandasamy, S., Baret, F., Verger, A., Neveux, P. and Weiss, M.: A comparison of methods for smoothing and gap filling time series of remote sensing observations - application to MODIS LAI products, Biogeosciences, 10(6), 4055-4071, doi:10.5194/bg-10-4055-2013, 2013.

Kang, L., Di, L., Deng, M., Shao, Y., Yu, G. and Shrestha, R.: Use of geographically weighted regression model for exploring spatial patterns and local factors behind NDVI-precipitation correlation, IEEE J. Sel. Top. Appl. Earth Obs.

15 Remote Sens., 7(11), 4530-4538, doi:10.1109/JSTARS.2014.2361128, 2014.

Landmann, T. and Dubovyk, O.: Mapping vegetation productivity dynamics and degradation trends over East Africa using a decade of medium Resolution MODIS time-series data, Int. Geosci. Remote Sens. Symp., 1801-1804, doi:10.1109/IGARSS.2013.6723149, 2013.

Li, H. and Yang, X.: Temperate dryland vegetation changes under a warming climate and strong human intervention - With

20 a particular reference to the district Xilin Gol, Inner Mongolia, China, Catena, 119, 9-20, doi:10.1016/j.catena.2014.03.003, 2014.

Liu, Y., Li, Y., Li, S. and Motesharrei, S.: Spatial and temporal patterns of global NDVI trends: Correlations with climate and human factors, Remote Sens., 7(10), 13233-13250, doi:10.3390/rs71013233, 2015.

Liu, Z., Notaro, M., Kutzbach, J. and Liu, N.: Assessing global vegetation - climate feedbacks from observations, J. Climate, 25 19, 787-814, doi:10.1175/JCLI3658.1, 2006.

Lu, L. and Shuttleworth, W. J.: Incorporating NDVI-Derived LAI into the Climate Version of RAMS and Its Impact on Regional Climate, J. Hydrometeorol., 3(3), 347-362, doi:10.1175/1525-7541(2002)003<0347:INDLIT>2.0.CO;2, 2002.

Maitima, J. M., Mugatha, S. M., Reid, R. S., Gachimbi, L. N., Majule, A., Lyaruu, H., Pomery, D., Mathai, S. and Mugisha, S.: The linkages between land use change, land degradation and biodiversity across East Africa, African J. Environ. Sci.

30 Technol., 3(10), 310-325, 2009.

Mandelbrot, B. B. and Wallis, J. R.: Robustness of the rescaled range R/S in the measurement of noncyclic long run statistical dependence, Water Resour. Res., 5, 967, doi:10.1029/WR005i005p00967, 1969.

Marshall, M., Funk, C. and Michaelsen, J.: Examining evapotranspiration trends in Africa, Clim. Dyn., 38(9-10), 18491865, doi:10.1007/s00382-012-1299-y, 2012. 
Hydrol. Earth Syst. Sci. Discuss., doi:10.5194/hess-2016-502, 2016

McNally, A., Shukla, S., Arsenault, K. R., Wang, S., Peters-Lidard, C. D. and Verdin, J. P.: Evaluating ESA CCI soil moisture in East Africa, Int. J. Appl. Earth Obs. Geoinf., 48, 1-14, doi:10.1016/j.jag.2016.01.001, 2016.

Montaldo, N., Albertson, J. D. and Mancini, M.: Vegetation dynamics and soil water balance in a water-limited Mediterranean ecosystem on Sardinia, Italy, Hydrol. Earth Syst. Sci. Discuss., 5, 219-255, doi:10.5194/hessd-5-219-2008, 52008.

Nataro, M., Wang, Y., Iu, Z. L., Gallimore, R. and Levis, S.: Combined statistical and dynamical assessment of simulated vegetation-rainfall interactions in North Africa during the mid-Holocene, Glob. Chang. Biol., 14(2), 347-368, doi:10.1111/j.1365-2486.2007.01495.x, 2008.

Navarra, A. and Tribbia, J.: The Coupled Manifold, J. Atmos. Sci., 62(2), 310-330, doi:10.1175/JAS-3345.1, 2005.

10 Ndayisaba, F., Guo, H., Bao, A., Guo, H., Karamage, F. and Kayiranga, A.: Understanding the Spatial Temporal Vegetation Dynamics in Rwanda, Remote Sens., 8(2), 129, doi:10.3390/rs8020129, 2016.

Nemani, R. R., Keeling, C. D., Hashimoto, H., Jolly, W. M., Piper, S. C., Myneni, C. J. T. R. B. and Running, S. W.: Climate-Driven Increases in Global Terrestrial Net Primary Production From 1982 to 1999, Science, 300(5625), 1560-1563, doi:10.1126/science.1082750, 2003.

15 Ning, T., Liu, W., Lin, W. and Song, X.: NDVI Variation and Its Responses to Climate Change on the Northern Loess Plateau of China from 1998 to 2012, Adv. Meteorol., 2015, 2015.

Notaro, M.: Statistical identification of global hot spots in soil moisture feedbacks among IPCC AR4 models, J. Geophys. Res. Atmos., 113(9), 1-8, doi:10.1029/2007JD009199, 2008.

Notaro, M. and Liu, Z.: Potential impact of the Eurasian boreal forest on North Pacific climate variability, J. Climate, 20(6),

20 981-992, doi:10.1175/JCLI4052.1, 2007.

Notaro, M., Liu, Z. and Williams, J. W.: Observed Vegetation-Climate Feedbacks in the United States, J. Climate, 19(1998), 763-786, doi:10.1175/JCLI3657.1, 2006.

Oguntunde, P. G., Abiodun, B. J., Lischeid, G. and Merz, C.: Modelling the impacts of reforestation on the projected hydroclimatology of Niger River Basin, West Africa, Ecohydrology, 7(1), 163-176, doi:10.1002/eco.1343, 2014.

25 Pfeifer, M., Platts, P. J., Burgess, N. D., Swetnam, R. D., Willcock, S., Lewis, S. L. and Marchant, R.: Land use change and carbon fluxes in East Africa quantified using earth observation data and field measurements, Environ. Conserv., 40(3), 241252, doi:10.1017/S0376892912000379, 2013.

Pfeifer, M., Lefebvre, V., Gonsamo, A., Pellikka, P. K. E., Marchant, R., Denu, D. and Platts, P. J.: Validating and linking the GIMMS leaf area index (LAI3g) with environmental controls in tropical Africa, Remote Sens., 6(3), 1973-1990,

30 doi:10.3390/rs6031973, 2014.

Pinzon, J. and Tucker, C.: A Non-Stationary 1981-2012 AVHRR NDVI3g Time Series, Remote Sens., 6(8), 6929-6960, doi:10.3390/rs6086929, 2014.

Pricope, N. G., Husak, G., Lopez-Carr, D., Funk, C. and Michaelsen, J.: The climate-population nexus in the East African Horn: Emerging degradation trends in rangeland and pastoral livelihood zones, Glob. Environ. Chang., 23(6), 1525-1541, 
Hydrol. Earth Syst. Sci. Discuss., doi:10.5194/hess-2016-502, 2016

Samanta, A., Knyazikhin, Y., Xu, L., Dickinson, R. E., Fu, R., Costa, M. H., Saatchi, S. S., Nemani, R. R. and Myneni, R. B.: Seasonal changes in leaf area of Amazon forests from leaf flushing and abscission, J. Geophys. Res. Biogeosciences, 117(1), 1-13, doi:10.1029/2011JG001818, 2012.

5 Sheffield, J., Goteti, G. and Wood, E. F.: Development of a 50-year high-resolution global dataset of meteorological forcings for land surface modeling, J. Climate, 19(13), 3088-3111, doi:10.1175/JCLI3790.1, 2006.

Snyder, P. K.: The influence of tropical deforestation on the Northern Hemisphere climate by atmospheric teleconnections, Earth Interact., 14(4), 1-34, doi:10.1175/2010EI280.1, 2010.

Snyder, P. K., Foley, J. A., Hitchman, M. H. and Delire, C.: Analyzing the effects of complete tropical forest removal on the

10 regional climate using a detailed three-dimensional energy budget: An application to Africa, J. Geophys. Res. D Atmos., 109(21), doi:10.1029/2003JD004462, 2004.

Tagesson, T., Fensholt, R., Guiro, I., Rasmussen, M. O., Huber, S., Mbow, C., Garcia, M., Horion, S., Sandholt, I., HolmRasmussen, B., Gottsche, F. M., Ridler, M. E., Olen, N., Lundegard Olsen, J., Ehammer, A., Madsen, M., Olesen, F. S. and Ardo, J.: Ecosystem properties of semiarid savanna grassland in West Africa and its relationship with environmental

15 variability, Glob. Chang. Biol., 21(1), 250-264, doi:10.1111/gcb.12734, 2015.

Teferi, E., Uhlenbrook, S. and Bewket, W.: Inter-annual and seasonal trends of vegetation condition in the Upper Blue Nile ( Abay ) Basin : dual-scale time, Earth Syst. Dyn., 6, 617-636, doi:10.5194/esd-6-617-2015, 2015.

Tong, X., Wang, K., Brandt, M., Yue, Y., Liao, C. and Fensholt, R.: Assessing Future Vegetation Trends and Restoration Prospects in the Karst Regions of Southwest China, Remote Sens., 8(5), 357, doi:10.3390/rs8050357, 2016.

20 Toté, C., Patricio, D., Boogaard, H., van der Wijngaart, R., Tarnavsky, E. and Funk, C.: Evaluation of satellite rainfall estimates for drought and flood monitoring in Mozambique, Remote Sens., 7(2), 1758-1776, doi:10.3390/rs70201758, 2015. Verhoef, A., Ottlé, C., Cappelaere, B., Murray, T., Saux-Picart, S., Zribi, M., Maignan, F., Boulain, N., Demarty, J. and Ramier, D.: Spatio-temporal surface soil heat flux estimates from satellite data; results for the AMMA experiment at the Fakara (Niger) supersite, Agric. For. Meteorol., 154, 55-66, doi:10.1016/j.agrformet.2011.08.003, 2012.

25 Wang, W., Chen, Y., Becker, S. and Liu, B.: Linear Trend Detection in Serially Dependent Hydrometeorological Data Based on a Variance Correction Spearman Rho Method, Water, 7, 7045-7065, doi:10.3390/w7126673, 2015.

White, F.: The vegetation of Africa - a descriptive memoir to accompany the Unesco/ AETFAT/UNSO vegetation map of Africa. Natural Resources Research Report XX., Paris, France., 1983.

Wi, L. Y., Zhang, J. Y. and Dong, W. J.: Vegetation effects on mean daily maximum and minimum surface air temperatures 30 over China, Chinese Sci. Bull., 56(9), 900-905, doi:10.1007/s11434-011-4349-7, 2011.

Williams, C. J. R. and Kniveton, D. R.: Atmosphere-land surface interactions and their influence on extreme rainfall and potential abrupt climate change over southern Africa, Clim. Change, 112(3), 981-996, doi:10.1007/s10584-011-0266-7, 2012.

Wilson, K. B., Baldocchi, D. D., Aubinet, M., Berbigier, P., Bernhofer, C., Dolman, H., Falge, E., Field, C., Goldstein, A., 
Hydrol. Earth Syst. Sci. Discuss., doi:10.5194/hess-2016-502, 2016 R., Oechel, W., Tenhunen, J., Valentini, R., Verma, S., Vesala, T. and Wofsy, S.: Energy partitioning between latent and sensible heat flux during the warm season at FLUXNET sites, Water Resour. Res., 38(12), 1-11, doi:10.1029/2001WR000989, 2002.

5 Wu, D., Zhao, X., Liang, S., Zhou, T., Huang, K., Tang, B. and Zhao, W.: Time-lag effects of global vegetation responses to climate change, Glob. Chang. Biol., 21(9), 3520-3531, doi:10.1111/gcb.12945, 2015.

Xue, Y., Boone, A. and Taylor, C. M.: Review of recent developments and the future prospective in West African atmosphere/land interaction studies, Int. J. Geophys., 2012, doi:10.1155/2012/748921, 2012.

Yuan, H., Dai, Y., Xiao, Z., Ji, D. and Shangguan, W.: Reprocessing the MODIS Leaf Area Index products for land surface

10 and climate modelling, Remote Sens. Environ., 115(5), 1171-1187, doi:10.1016/j.rse.2011.01.001, 2011.

Yue, S. and Wang, C. Y.: Applicability of prewhitening to eliminate the influence of serial correlation on the Mann-Kendall test, Water Resour. Res., 38(6), 4-1-4-7, doi:10.1029/2001WR000861, 2002.

Yue, S., Pilon, P., Phinney, B. and Cavadias, G.: The influence of autocorrelation on the ability to detect trend in hydrological series, Hydrol. Process., 16(9), 1807-1829, doi:10.1002/hyp.1095, 2002.

15 Zeng, F.-W., Collatz, G., Pinzon, J. and Ivanoff, A.: Evaluating and Quantifying the Climate-Driven Interannual Variability in Global Inventory Modeling and Mapping Studies (GIMMS) Normalized Difference Vegetation Index (NDVI3g) at Global Scales, Remote Sens., 5(8), 3918-3950, doi:10.3390/rs5083918, 2013.

Zhang, J., Wang, W.-C. and Wu, L.: Land-atmosphere coupling and diurnal temperature range over the contiguous United States, Geophys. Res. Lett., 36(6), 1-6, doi:10.1029/2009GL037505, 2009.

20 Zhang, J., Wu, L. and Dong, W.: Land-atmosphere coupling and summer climate variability over East Asia, J. Geophys. Res. Atmos., 116(5), 1-14, doi:10.1029/2010JD014714, 2011.

Zhao, Z., Gao, J., Wang, Y., Liu, J. and Li, S.: Exploring spatially variable relationships between NDVI and climatic factors in a transition zone using geographically weighted regression, Theor. Appl. Climatol., 120(3-4), 507-519, doi:10.1007/s00704-014-1188-x, 2014.

25 Zheng, X. and Eltahir, E. A. B.: The role of vegetation in the dynamics of West African monsoons, J. Climate, 11(8), 20782096, doi:10.1175/1520-0442-11.8.2078, 1998.

Zhou, L., Dickinson, R. E., Tian, Y., Vose, R. S. and Dai, Y.: Impact of vegetation removal and soil aridation on diurnal temperature range in a semiarid region: application to the Sahel., Proc. Natl. Acad. Sci. U. S. A., 104(46), 17937-17942, doi:10.1073/pnas.0700290104, 2007.

30 Zhu, Z., Bi, J., Pan, Y., Ganguly, S., Anav, A., Xu, L., Samanta, A., Piao, S., Nemani, R. R. and Myneni, R. B.: Global data sets of vegetation leaf area index (LAI)3g and fraction of photosynthetically active radiation (FPAR)3g derived from global inventory modeling and mapping studies (GIMMS) normalized difference vegetation index (NDVI3G) for the period 1981 to 2, Remote Sens., 5(2), 927-948, doi:10.3390/rs5020927, 2013. 
Hydrol. Earth Syst. Sci. Discuss., doi:10.5194/hess-2016-502, 2016

Manuscript under review for journal Hydrol. Earth Syst. Sci.

Published: 19 October 2016

Table 1: Classification of vegetation dynamics persistence based on LAI trends (1982-2011) and the $H$ value

\begin{tabular}{|c|c|c|}
\hline $\begin{array}{ll}\text { Trend } & \mathrm{H} \\
\end{array}$ & Persistent $(0.5<\mathrm{H}<1)$ & Anti-Persistent $(0<\mathrm{H}<0.5)$ \\
\hline Increasing $(p<0.05)$ & Positive Development (PD) & $\begin{array}{l}\text { Anti-persistent Positive } \\
\text { Development (APD) }\end{array}$ \\
\hline $\begin{array}{l}\text { Steady Increase } \\
\quad(p \geq 0.05)\end{array}$ & $\begin{array}{l}\text { Sustained and Steady Positive } \\
\text { Development (SSPD) }\end{array}$ & \multirow{2}{*}{ Undetermined Development (UD) } \\
\hline $\begin{array}{l}\text { Steady Decrease } \\
(p \geq 0.05)\end{array}$ & $\begin{array}{l}\text { Sustained and Steady Negative } \\
\text { Development (SSND) }\end{array}$ & \\
\hline Decreasing $(p<0.05)$ & Negative Development (ND) & $\begin{array}{l}\text { Anti-persistent Negative } \\
\text { Development (AND) }\end{array}$ \\
\hline
\end{tabular}

Table 2: Comparison of model performance between OLS and GWR

\begin{tabular}{|c|c|c|c|c|c|c|}
\hline \multirow{2}{*}{\multicolumn{2}{|c|}{ Model }} & \multirow[b]{2}{*}{$\mathrm{AICc}$} & \multicolumn{3}{|c|}{ Adjusted } & \multirow{2}{*}{$\begin{array}{l}\text { Moran's } \\
\text { I }\end{array}$} \\
\hline & & & $\mathrm{R}^{2}$ & $\mathrm{R}^{2}$ & Sigma & \\
\hline \multirow{2}{*}{ I } & OLS & 12051.81 & 0.68 & 0.68 & 0.56 & 0.53 \\
\hline & GWR & 4197.91 & 0.94 & 0.91 & 0.25 & -0.023 \\
\hline \multirow{2}{*}{ II } & OLS & 13801.64 & 0.59 & 0.59 & 0.63 & 0.63 \\
\hline & GWR & 4241.29 & 0.92 & 0.91 & 0.28 & -0.020 \\
\hline & OLS & 45904.85 & 0.73 & 0.73 & 5.92 & 0.70 \\
\hline & GWR & 30113.92 & 0.98 & 0.98 & 1.52 & 0.004 \\
\hline & OLS & 29926.90 & 0.97 & 0.97 & 1.94 & 0.85 \\
\hline & GWR & 9086.04 & 1.00 & 1.00 & 0.34 & -0.015 \\
\hline
\end{tabular}

Table 3: Descriptive statistic of parameter estimates for models I and IV from both OLS and GWR

\begin{tabular}{clcc|ccc}
\hline Model & \multicolumn{3}{c|}{ OLS } & \multicolumn{3}{c}{ GWR } \\
\hline \multirow{4}{*}{ I } & Variable & Estimate Std Err & $25 \%$ quartile Median $75 \%$ quartile \\
& Intercept & 2.225 & 0.100 & -4.997 & 0.716 & 5.851 \\
& API $_{\text {DJF }}$ & 0.121 & 0.003 & -0.075 & 0.034 & 0.150 \\
& API $_{\text {MAM }}$ & -0.041 & 0.003 & -0.069 & 0.017 & 0.117 \\
& TMIN $_{\text {DJF }}$ & -0.083 & 0.010 & -0.729 & 0.043 & 0.887 \\
& TMIN $_{\text {MAM }}$ & 0.231 & 0.011 & -0.958 & -0.150 & 0.684 \\
& TMAX $_{\text {MAM }}-0.168$ & 0.006 & -0.453 & 0.006 & 0.437
\end{tabular}


Hydrol. Earth Syst. Sci. Discuss., doi:10.5194/hess-2016-502, 2016

Manuscript under review for journal Hydrol. Earth Syst. Sci.

Published: 19 October 2016

(c) Author(s) 2016. CC-BY 3.0 License.

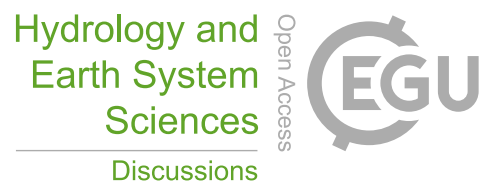
(c)

\begin{tabular}{llcc|ccc} 
& Intercept & 17.610 & 0.296 & -7.327 & 3.879 & 13.857 \\
& LAI $_{\text {DJF }}$ & -0.205 & 0.086 & -0.930 & -0.144 & 0.560 \\
& LAI $_{\text {MAM }}$ & -0.301 & 0.090 & -0.461 & 0.235 & 1.001 \\
IV & API $_{\text {DJF }}$ & 1.038 & 0.004 & 0.972 & 1.076 & 1.231 \\
TMIN $_{\text {DJF }}$ & 1.507 & 0.031 & -1.870 & -0.128 & 1.456 \\
& TMIN $_{\text {MAM }}$ & -0.532 & 0.040 & -1.378 & 0.250 & 2.092 \\
TMAX $_{\text {MAM }}$ & -1.102 & 0.018 & -1.087 & -0.144 & 0.650 \\
\hline
\end{tabular}

5 Table 4: ANOVA comparison results for models I and IV

\begin{tabular}{clcccc}
\hline Model & \multicolumn{1}{c}{ Source } & SS & DF & MS & F \\
\hline \multirow{2}{*}{ I } & Global Residuals & 2248.321 & 7172.00 & & \\
& GWR Improvement & 1789.629 & 1831.542 & 0.977 & \\
& GWR Residuals & 458.692 & 5340.458 & 0.086 & 11.376 \\
\hline \multirow{2}{*}{ IV } & Global Residuals & 27117.103 & 7171 & & \\
& GWR Improvement & 26305.601 & 2125.145 & 12.378 & \\
& GWR Residuals & 811.502 & 5045.855 & 0.161 & 76.967 \\
\hline
\end{tabular}


Hydrol. Earth Syst. Sci. Discuss., doi:10.5194/hess-2016-502, 2016

Manuscript under review for journal Hydrol. Earth Syst. Sci.

Published: 19 October 2016

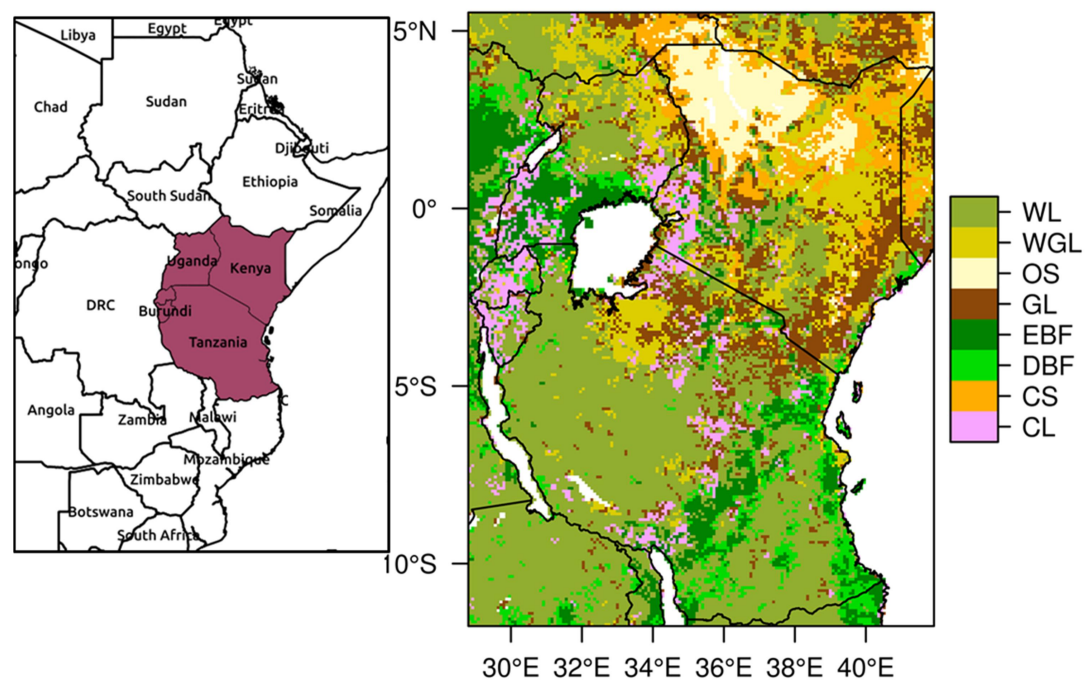

Figure 1: Location of the study area and land cover types defined using the International Geosphere-Biosphere Programme classification scheme (EBF: evergreen broadleaf forest; DBF: deciduous broadleaf forest; WL: Woodland; WGL: Wooded 
Hydrol. Earth Syst. Sci. Discuss., doi:10.5194/hess-2016-502, 2016

Manuscript under review for journal Hydrol. Earth Syst. Sci.

Published: 19 October 2016
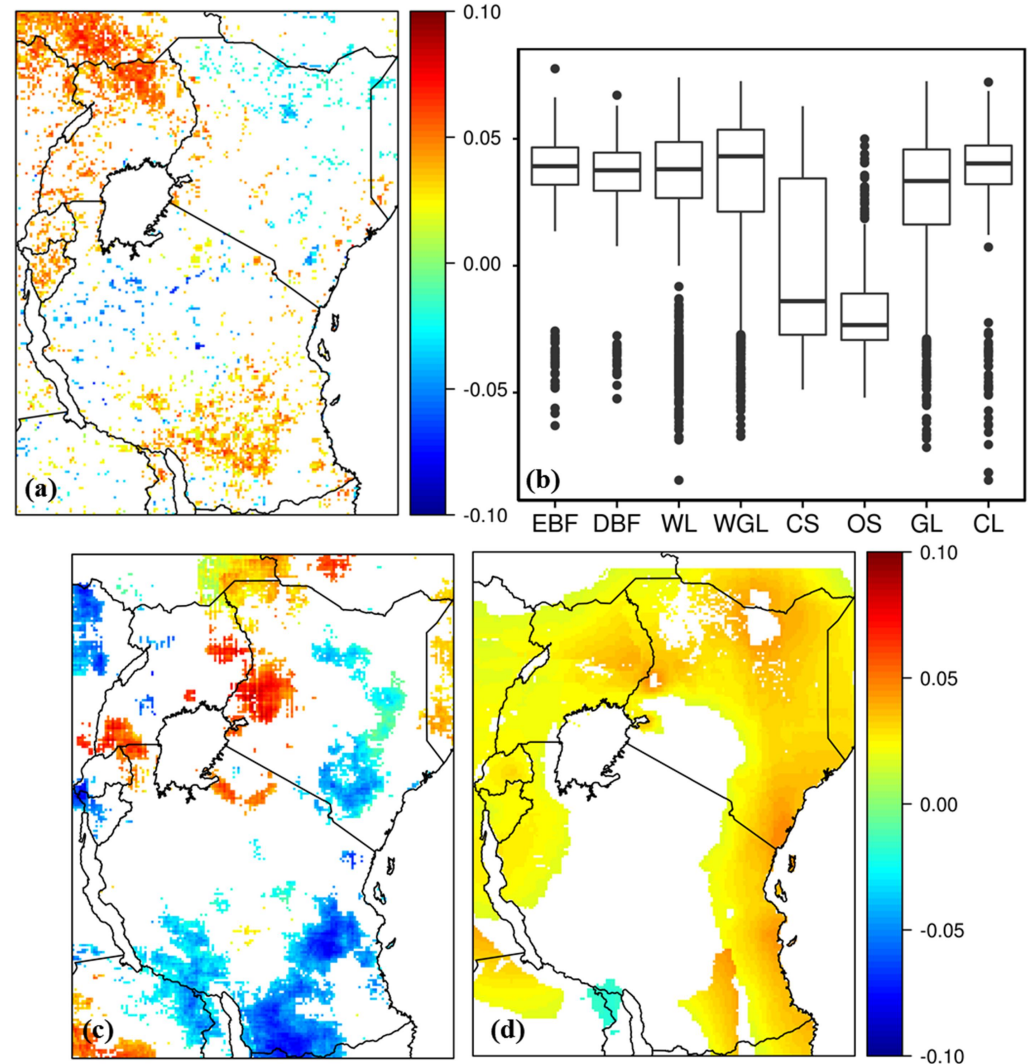

Figure 2: Spatial patterns of long term trends in standardized anomalies of LAI, API and Tmin (a, c \& d, respectively), and LAI trend for different land cover types (b). The trends are in standardized units per year and only significant trends at $95 \%$ significance level are shown. 
Hydrol. Earth Syst. Sci. Discuss., doi:10.5194/hess-2016-502, 2016

Manuscript under review for journal Hydrol. Earth Syst. Sci.

Published: 19 October 2016

(c) Author(s) 2016. CC-BY 3.0 License.

\section{Hydrology and Earth System Sciences \\ Discussions}

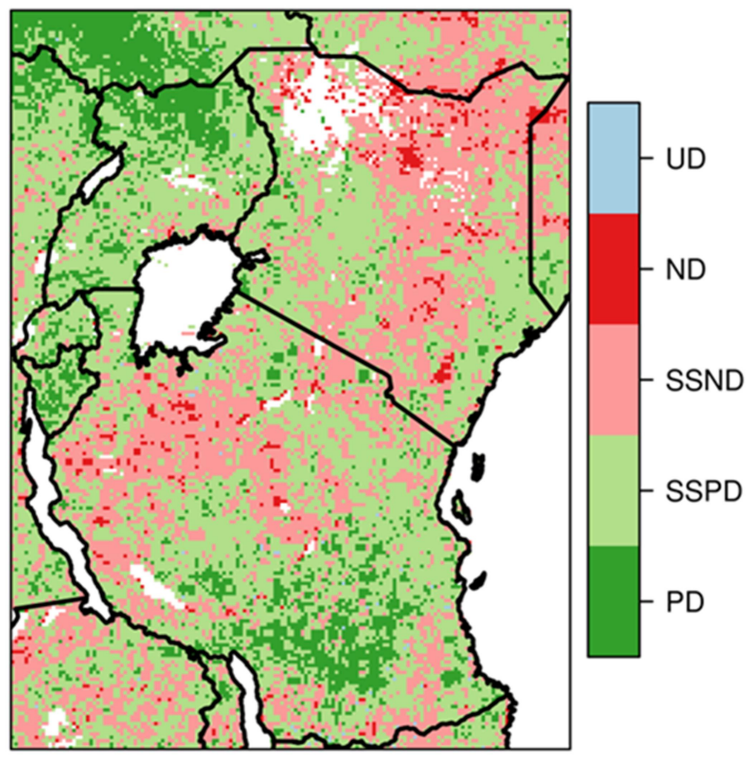

Figure 3: Spatial distribution of persistence of LAI trends (the abbreviations in the legend are defined as Positive Development (PD), Sustained and Steady Positive Development (SSPD), Sustained and Steady Negative Development (SSND), Negative Development (ND) and Undetermined Development (UD))
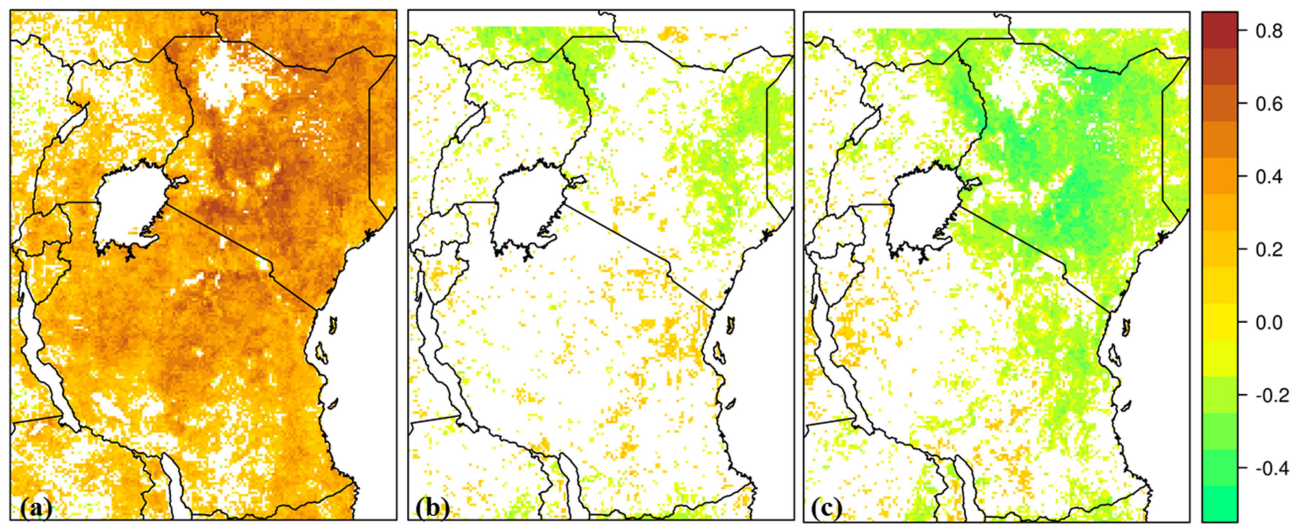

Figure 4: Instantaneous correlations between monthly LAI anomalies and monthly anomalies of (a) API, (b) Minimum temperature, and $(c)$ Maximum temperature. Only significant $(p=0.05)$ correlations are shown. 
Hydrol. Earth Syst. Sci. Discuss., doi:10.5194/hess-2016-502, 2016

Manuscript under review for journal Hydrol. Earth Syst. Sci.

Published: 19 October 2016
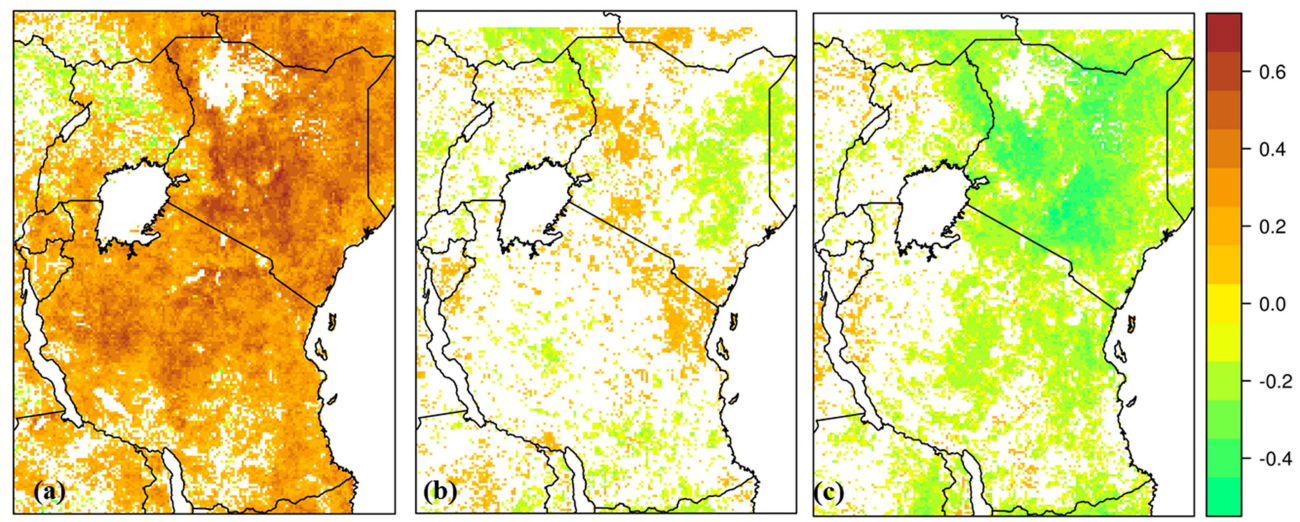

Figure 5: Maximum correlation coefficient between anomalies of LAI and leading (a) API, (b) minimum temperature and (c) maximum temperature anomalies at one to three leading months. Only significant $(p=0.05)$ correlations are shown.
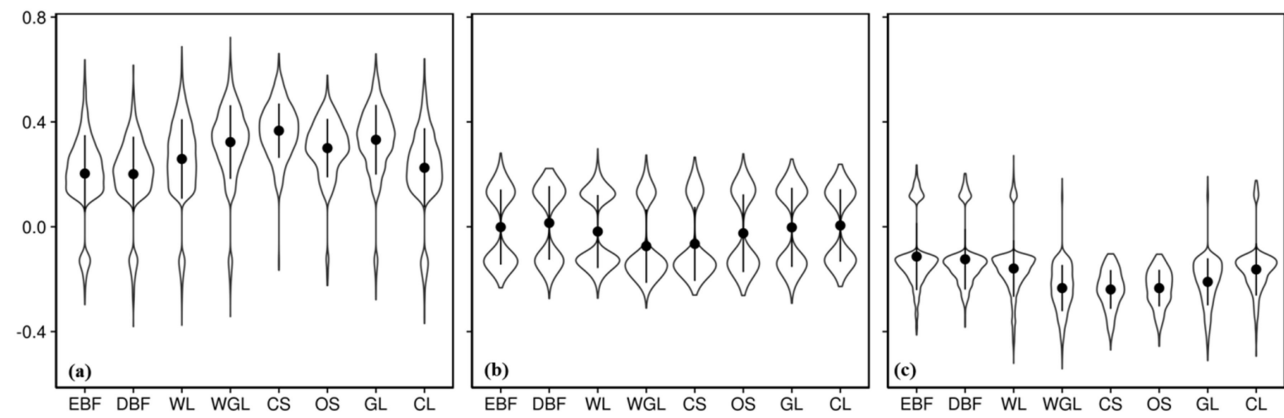

Figure 6: Distribution of correlation coefficient in different landcover types with leading (a) API, (b) Tmin and (c) Tmax. Only significant $(p=0.05)$ correlations are shown. 
Hydrol. Earth Syst. Sci. Discuss., doi:10.5194/hess-2016-502, 2016

Manuscript under review for journal Hydrol. Earth Syst. Sci.

Published: 19 October 2016
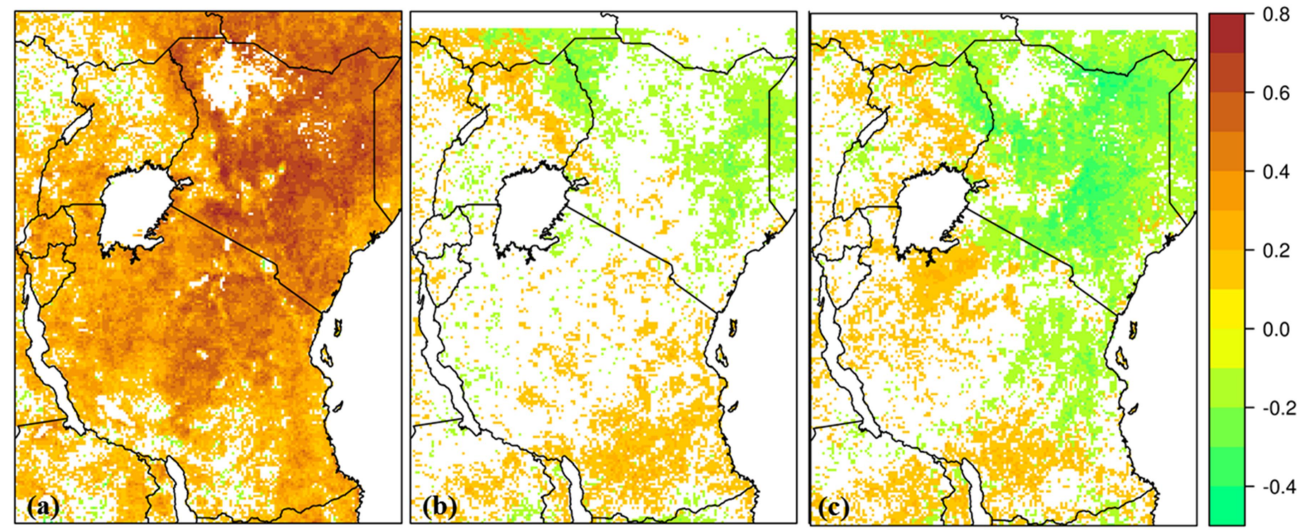

Figure 7: Maximum correlation coefficient between leading LAI and (a) API, (b) minimum temperature and (c) maximum temperature anomalies at one to three month lags. Only significant $(p=0.05)$ correlations are shown.
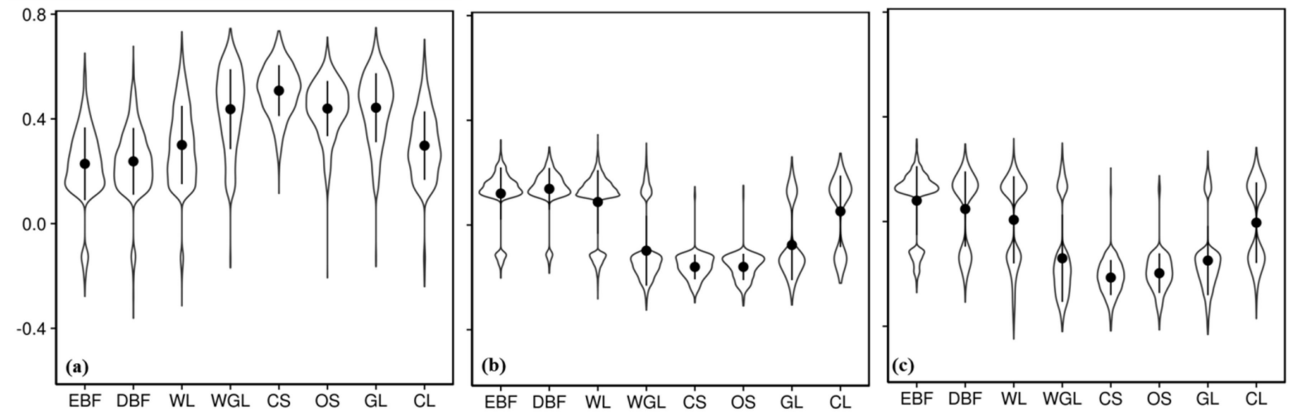

Figure 8: Distribution of correlation coefficient in different landcover types between leading LAI and (a) API, (b) Tmin and (c) Tmax. Only significant $(p=0.05)$ correlations are shown. 
Hydrol. Earth Syst. Sci. Discuss., doi:10.5194/hess-2016-502, 2016

Manuscript under review for journal Hydrol. Earth Syst. Sci.

Published: 19 October 2016
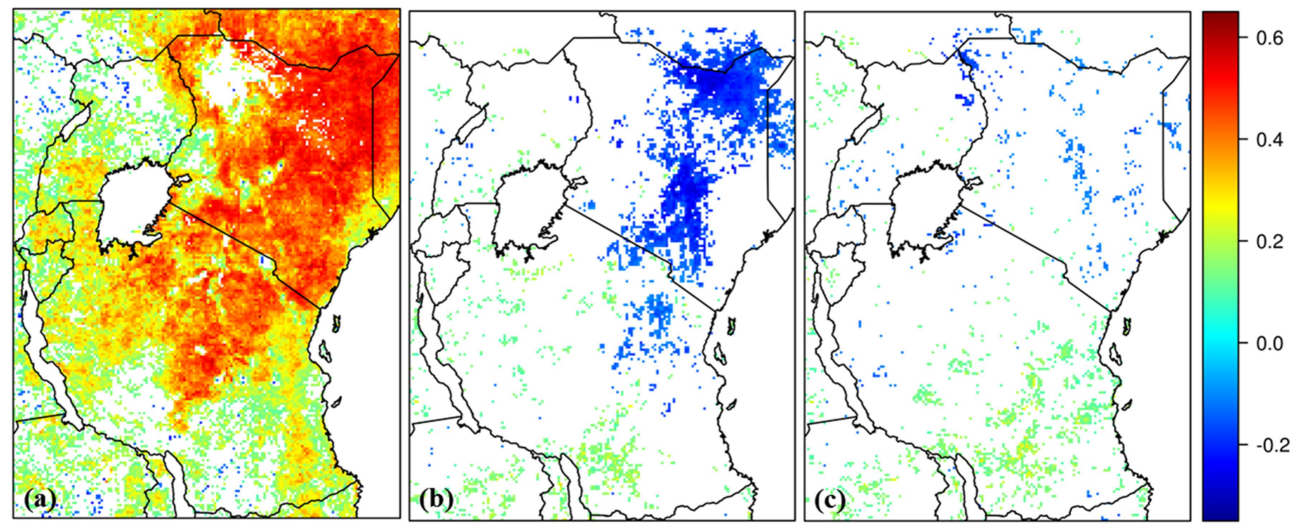

Figure 9: LAI feedback efficiency on (a) API, (b) Tmin and (c) Tmax. Mean feedback efficiency is computed as the weighted average of the feedback efficiencies at one to three-month lags. Only significant $(p=0.05)$ efficiency values are shown.
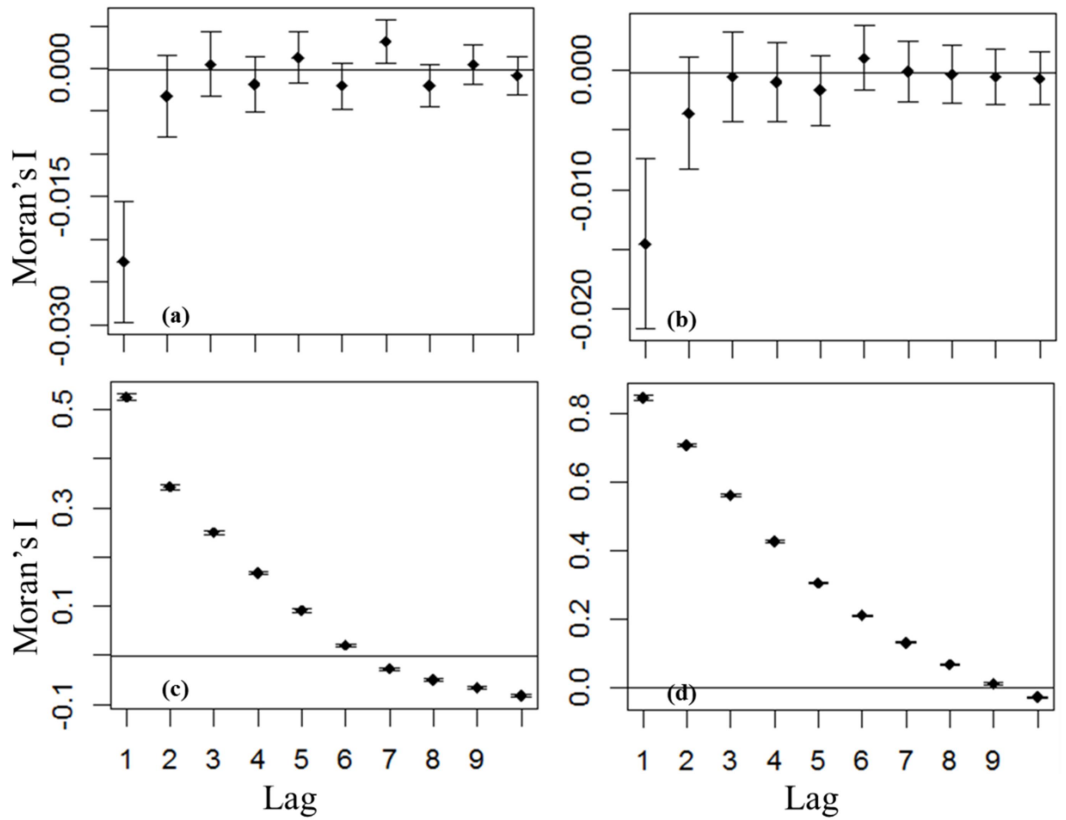

Figure 10: Spatial correlograms for residuals of models I and IV for GWR (a-b) and OLS (c-d). 